\title{
Vaginal microbiota and the potential of Lactobacillus derivatives in maintaining vaginal health
}

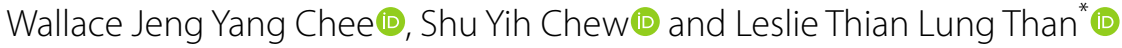

\begin{abstract}
Human vagina is colonised by a diverse array of microorganisms that make up the normal microbiota and mycobiota. Lactobacillus is the most frequently isolated microorganism from the healthy human vagina, this includes Lactobacillus crispatus, Lactobacillus gasseri, Lactobacillus iners, and Lactobacillus jensenii. These vaginal lactobacilli have been touted to prevent invasion of pathogens by keeping their population in check. However, the disruption of vaginal ecosystem contributes to the overgrowth of pathogens which causes complicated vaginal infections such as bacterial vaginosis (BV), sexually transmitted infections (STIs), and vulvovaginal candidiasis (VVC). Predisposing factors such as menses, pregnancy, sexual practice, uncontrolled usage of antibiotics, and vaginal douching can alter the microbial community. Therefore, the composition of vaginal microbiota serves an important role in determining vagina health. Owing to their Generally Recognised as Safe (GRAS) status, lactobacilli have been widely utilised as one of the alternatives besides conventional antimicrobial treatment against vaginal pathogens for the prevention of chronic vaginitis and the restoration of vaginal ecosystem. In addition, the effectiveness of Lactobacillus as prophylaxis has also been well-founded in long-term administration. This review aimed to highlight the beneficial effects of lactobacilli derivatives (i.e. surface-active molecules) with anti-biofilm, antioxidant, pathogen-inhibition, and immunomodulation activities in developing remedies for vaginal infections. We also discuss the current challenges in the implementation of the use of lactobacilli derivatives in promotion of human health. In the current review, we intend to provide insights for the development of lactobacilli derivatives as a complementary or alternative medicine to conventional probiotic therapy in vaginal health.
\end{abstract}

Keywords: Vaginal microbiota, Vaginal ecosystem, Probiotic, Lactobacillus, Lactobacillus derivatives, Surface-active molecules

\section{Background}

Human Microbiome Project (HMP) and Integrative HMP (iHMP) were funded by the National Institutes of Health (NIH). They are interdisciplinary effort that engaged in human microbiome profiling for gut, vaginal, oral, and skin communities $[1,2]$. Both projects aimed to unravel the characteristics, distributions, and metagenomics of

\footnotetext{
*Correspondence: leslie@upm.edu.my
}

Department of Medical Microbiology, Faculty of Medicine and Health

Sciences, Universiti Putra Malaysia, 43400 Serdang, Selangor, Malaysia microbes from those anatomical sites [3]. The findings from HMP are deemed significant to establish the relationship between microbiota changes and pathogenesis of disease, as well as to identify the biomarkers for diagnostic purpose [4].

Human vaginal microbiota comprises a diverse array of beneficial microbes and opportunistic pathogens that inhabit the vaginal milieu $[5,6]$. In order to understand the microbiota within human vagina, multiple approaches involving "-omics" technologies have been developed. Molecular approaches that are commonly 
employed to study the microbial communities are polymerase chain reaction-denaturing gradient gel electrophoresis (PCR-DGGE), DNA pyrosequencing, fluorescence insitu hybridisation (FISH), quantitative PCR, and microarrays [Reviewed in [7]]. Besides, other modern "-omics" technologies such as metabolomics, metagenomics, metatranscriptomics, and proteomics have begun to reinvigorate research into the discovery of functional activity in the microbial communities [8]. The integration of modern multiomic data is able to decipher the functional insights from complex microbial comuunities through the association of microbial and metabolic profiles with the role in mediating human health [8]. To date, the vast majority of the human microbiota studies utilised 16S rRNA gene sequencing in the identification of complex microbial communities due to its feasibility in inferring the representation of certain microbial communities that cause diseases [9]. Since the advent of technological advances in assessing human microbial diversity, Ravel et al. [10] have successfully identified five distinct bacterial communities by using advanced high-throughput sequencing technology. The indigenous microbiota in the vaginal milieu is believed to be in a symbiotic relationship with the host [11]. Fungi, especially Candida species are likely to exist as commensals in the mucous layer of vagina and they form part of the complex vaginal ecosystem with other bacteria $[12,13]$. It is suggested that the fluctuation of microbiota and mycobiota composition in women of reproductive age contributed to the temporal dynamics in vaginal communities [11]. In fact, this fluctuation is influenced by hormonal changes, age, sexual practices, and antimicrobial drugs usage [14-17]. The microbial dysbiosis in vagina leads to overgrowth of opportunistic pathogens and ultimately contributes to the onset of disease [18].

Vaginal dysbiosis reflects the disruption of microbial community in vagina and is frequently associated with several gynaecological diseases. Multiple studies have shown the association between vaginal dysbiosis and increased vaginal infections such as bacterial vaginosis (BV), vulvovaginal candidiasis (VVC), sexually transmitted infections (STIs), i.e. trichomoniasis, human papillomavirus (HPV) infection, Chlamydia trachomatis (CT) infection, human immunodeficiency virus (HIV) susceptibility, and genital herpes infection [19-23]. One of the most prominent features of vaginal dysbiosis is the changes in vaginal $\mathrm{pH}$. In a recent study, a significantly higher vaginal $\mathrm{pH}$ caused by decreased in lactate concentration was reported among BV, CT, and VVC patients as compared to healthy women [24]. The shift of microbial communities in vagina can also lead to severe gynaecological issues such as pregnancy loss, preterm labour, and low conception rates if left unattended [25]. Collectively, maintaining a harmonious balance of vaginal microbiota is crucial for a robust host-microbial interaction that promotes healthy vaginal ecosystem.

The knowledge advancement in human microbiota has accelerated the pace of new ventures in live biotherapeutics using beneficial microorganisms [26]. Previously, live biotherapeutics via faecal microbiota transplantation (FMT) has been proven successful in treating recurrent Clostridioides difficile infection [27]. Owing to the success of FMT, a similar approach using vaginal microbiota transplantation (VMT) could be effective in treating problematic vaginal infections. Recently, the first VMT has been reported to be able to reconstitute Lactobacillus-dominated microbiota with no observable adverse effects in recurrent-BV patients [28]. In addition, patients receiving Lactobacillus co-administered with antibiotics also showed reduced proneness towards recurrent BV [29]. In a similar study, a combined therapy using metronidazole with both $L$. rhamnosus GR-1 and L. reuteri RC-14 has successfully treated $88 \%$ of BV patients, as compared to $40 \%$ recovery rate for patients receiving only metronidazole treatment [30]. It has been suggested that these beneficial effects are partly associated with the cell surface-active molecules (SAMs) such as peptidoglycan (PG), lipoteichoic acid (LTA), biosurfactants (BS) and exopolysaccharides (EPS) [31, 32]. In fact, Lactobacillus SAMs has been proved to antagonise a plethora of bacterial and fungal pathogens such as Candida albicans, Staphylococcus aureus, Streptococcus mutans, Escherichia coli, Pseudomonas aeruginosa, and Salmonella typhimurium [33-35]. Therefore, further understanding in Lactobacillus and its derivatives (i.e. SAMs) could pave way for the development of novel remedy for infections caused by vaginal dysbiosis.

Over the past decade, investigations on vaginal microbiota have increased exponentially. These studies revealed the diversity of microbial communities that shaped up the distinct composition of vagina microflora in women [10, 24, 36-38]. The common findings from these studies suggested that Lactobacillus-dominated community is likely to be observed in the healthy-state vagina and higher vaginal $\mathrm{pH}$ (less acidic) is reported in diseased-state vagina. Besides, the microbial composition of vagina in some women are highly dynamic due to several predisposing host factors that eventually affects the host-microbial interaction. To date, the single root cause for vaginal dysbiosis should there be one remains to be identified. In this review, we seek to provide an overview of indigenous vaginal microbiota and mycobiota in women. Besides, we endeavour to underline the potential role of Lactobacillus and its derivatives (i.e. SAMs) 
in keeping vaginal pathogens under control to promote vaginal health.

\section{Indigenous vaginal microbiota in women}

Healthy human vagina that is dominated by lactobacilli has been reported with marginal presence of fungi taxa [39]. Generally, beneficial bacteria communities coexist with human host in mutualism by protecting host vaginal milieu from colonisation of pathogenic microorganisms while the host provides nutrients for bacterial growth [11]. Colonisation and dominance of lactobacilli are essential traits of a healthy vaginal microbiota, commonly by species such as Lactobacillus crispatus, Lactobacillus gasseri, Lactobacillus iners, and Lactobacillus jensenii $[10,40,41]$. The changes in the microbiota composition of human vagina can occur through different life stages, this includes infant, puberty, pregnancy, and menopause stages [42]. In fact, hormonal changes, uncontrolled usage of antibiotics, menstruation, and vaginal douching are the common factors that steered the temporal changes in human vaginal microbiota $[6,43,44]$.

Relative abundances of the predominant lactic acid bacteria ( $\mathrm{LAB}$ ) in healthy vagina determine the type of bacteria community groups, known as community state types (CSTs) [10]. The CSTs are grouped as CST I, II, III, IV, V, respectively with each of the CSTs is dominated by $L$. crispatus, L. gasseri, L. iners, polymicrobial flora including Lactobacillus and bacterial vaginosis-associated bacteria (BVAB), and L. jensenii (Fig. 1) $[6,10]$. While CST I, III, and IV have been extensively studied and are commonly found in women, CST II and V, however, are rarely found in women $[45,46]$. In fact, DiGiulo et al. [47] and van de Wijgert et al. [46], in their studies reported that vaginal microbiota from healthy women partly belongs to CST II and V. Gajer et al. [6] further characterised CST IV (lacks of significant abundance of particular Lactobacillus species) into subgroups CST IV-A and CST IV-B [6]. According to Gajer et al., CST IV-A generally contains a modest proportion of $L$. iners along with anaerobic bacteria such as Corynebacterium, Finegoldia, Streptococcus, or Anaerococcus whereas CST IV-B has a significant higher number of BVAB [6].

The presence of lactobacilli in vagina orchestrates a distinct inflammatory paradigm that contributed to distinct CSTs. It is noteworthy to mention that the presence of L. iners in CST III and CST IV were associated with higher baseline in pro-inflammatory factors such as macrophage migration inhibitory factor (MIF), interleukin- $1 \alpha$, interleukin 18 , and tumour necrosis factor-alpha (TNF- $\alpha$ ) which are responsible for the activation of inflammatory responses in vagina [48]. Lactobacillus crispatus-dominated vaginal microbiota (CST I) is always associated with healthy vagina, while $L$. iners-dominated vaginal milieu (CST III) is more prone to vaginal dysbiosis (Fig. 1) [49, 50]. Multiple studies have shown that the protective effect of $L$. crispatus against STIs, BV, and VVC, are intrinsically associated with the ability to produce lactic acid and bacteriocin that maintain the healthy state of vagina [51,52]. Meanwhile, the lack of essential amino acids synthesis repertoire in $L$. iners has forced it to heavily rely on the exogenous amino acids derived from host [53]. Its restricted metabolic repertoire and dependence on the nutrients from host render it to be highly sensitive to environmental change [53]. Besides, it also produced a distinct isomeric form of lactic acid (L-lactic acid) which is insufficient to inhibit the progression of pathogens during vaginal infection [54, 55]. Additionally, a profusion of research have shown that human vaginal composition differs considerably between individuals, and greatly influenced by hormones (e.g. pregnancy and menses), as well as ethnicity $[10,56]$. The influence of hormones particularly oestradiol, as a matter of fact, can stimulate the transition of CST I (L. crispatus-dominated) to CST III (L. iners-dominated) or mixed lactobacilli community, but rarely to diseased-state vaginal community (Fig. 1) [6, 46]. In addition, diseased-state (CST IV) and facilitated-BV state (CST III) vaginal community were more commonly found in sub-Saharan African $[6,10]$. It is conceivable that genetic factors in these groups may alter the vaginal immune responses which favours the colonisation of $L$. iners and pathobionts that cause vaginal dysbiosis [56, 57]. As has been noted, the characterisation of microbial community in vagina has vastly extended our knowledge on the relationship between healthy and abnormal vaginal microbiota. The identification of prophage in L. iners genome indicated that bacteriophage could influence the adaptation strategies and abundance of lactobacilli in the vaginal ecosystem [58]. Thus, future studies are needed to elucidate the presence of Lactobacillus phage and its contribution to the healthy- and diseased-state vagina.

The core vaginal microbiota of majority Asian and white women is dominated by $80.2 \%$ and $89.7 \%$ of lactobacilli, respectively [10]. In contrast, Lactobacillus is not the sole genus that dominates vaginal microbiota in black and Hispanic women (only 59.6\% and 61.9\%, respectively) [10]. A cross-sectional study of 151 women (65 HPV-positive, 86 HPV-negative) revealed that HPV is significantly associated with higher abundance of anaerobes like Bacteroides plebeius, Acinetobacter lwoffii, and Prevotella buccae [59]. This finding implied that higher diversity of vaginal microbiota significantly increased the risk of HPV acquisition [59]. It is conceivable that disrupted vaginal microbiota may affect the host innate immunity against HPV infection that leads to development of cervical cancer [60]. In addition, Lee et al. [61] also 

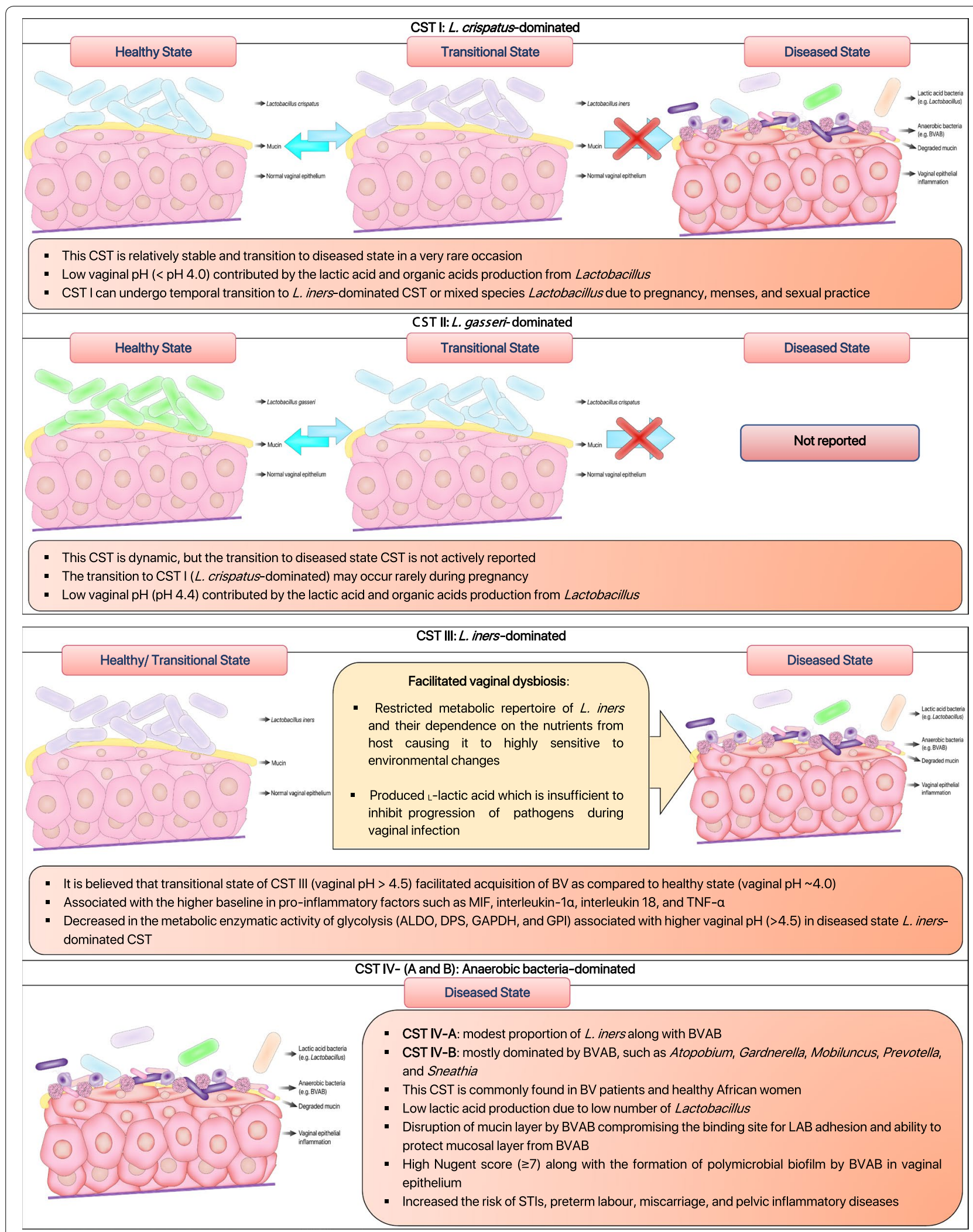

Fig. 1 Schematic illustration of the human vaginal community state types (CSTs) based on scientific literature. The healthy and diseased state of vaginal microbiota can be classified into five common CSTs according to their respective characteristics. These CSTs are dominated mainly $L$. crispatus, L. gasseri, L. iners, bacterial vaginosis-associated bacteria (BVAB), and L.jensenii $[6,10,47,96,262,263]$ 


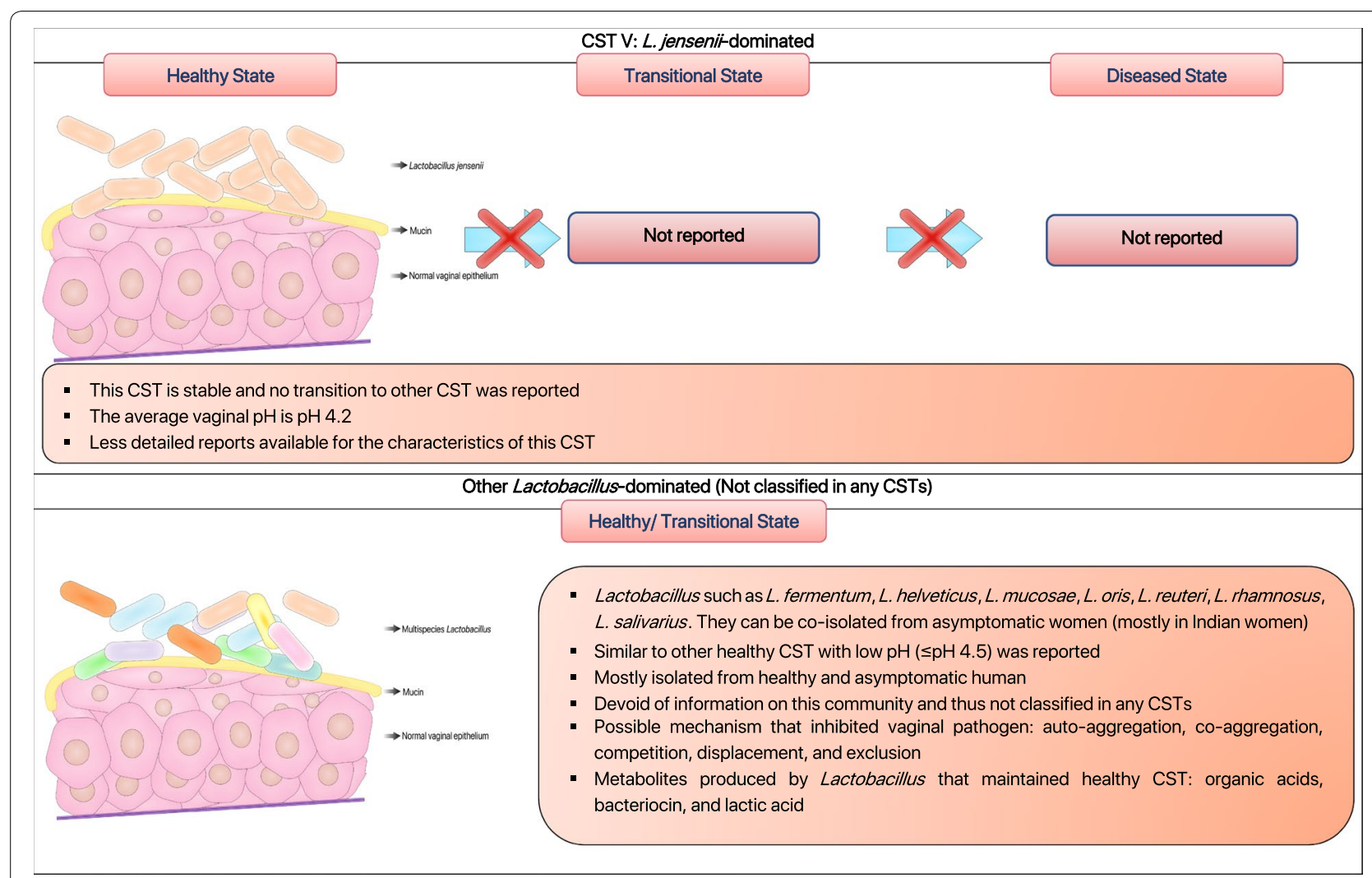

Fig. 1 continued

revealed that vaginal dysbiosis is strongly interconnected with HPV acquisition. The vaginal microbiota of HPVinfected women has higher abundance of Prevotella, Sneathia, Dialister, and Bacillus with lower abundance of Lactobacillus as compared to healthy women [61]. Furthermore, disrupted vagina microbiota, characterised by low abundance of Lactobacillus and predominance of G. vaginalis was significantly associated with HPV acquisition and cervical neoplasia development [62]. Besides, low abundance of Lactobacillus and high proportions of Gardnerella, Brucella, Sneathia, and other miscellaneous bacteria in vagina were common among HPV- and genital warts-infected patients [63]. Taken together, the vaginal microbiota imbalance is strongly correlated with the risk of HPV-related infection. In short, the interventional treatment for vaginal dysbiosis could reduce the HPV acquisition and cervical cancer development [64].

In contrast to vaginal microbiota profiling, human vaginal mycobiota is still underexamined. The first highthroughput sequencing on vaginal mycobiota was only carried out in 2013 by Drell and her colleagues [39]. According to Drell et al. [39], 196 fungal operational taxonomic units (OTUs) were obtained from healthy Estonian women; the most dominant phyla was Ascomycota
(58.0\%), followed by unspecified fungal OTUs (39.0\%), and Basidiomycota (3.0\%). The most common OTUs that dominated phylum Ascomycota (order Saccharomycetales) are genus Candida (37.0\%), mainly C. albicans (34.1\%), Candida krusei (2.3\%), Candida alimentaria (reported as Candida sp. VI04616 in this study) (0.3\%), Candida parapsilosis (0.3\%), and Candida dubliniensis (0.04\%) [39]. Similarly, few studies also showed that Candida community are found in asymptomatic and healthy women [65, 66]. In addition, Ward et al. [67] reported that infants have an identical dominant mycobiota fungal species as the mother's vagina (C. albicans) regardless of the methods of delivery [67]. Furthermore, C. albicans colonisation in infants is evident following vertical transmission from their mothers [68]. All in all, these findings indicate that $C$. albicans can colonise vagina without causing any symptomatic infections. At the same time, an increasing number of studies also highlighted risk factors such as hormones, diabetes, oral sex, intravaginal douching, self-treatment with antifungals and antibiotics, usage of intrauterine devices, and perineal laceration to be significantly associated with VVC occurrence [69-71]. Selected publications on human microbiome profiling on vaginal-related infections are summarised as in Table 1. 


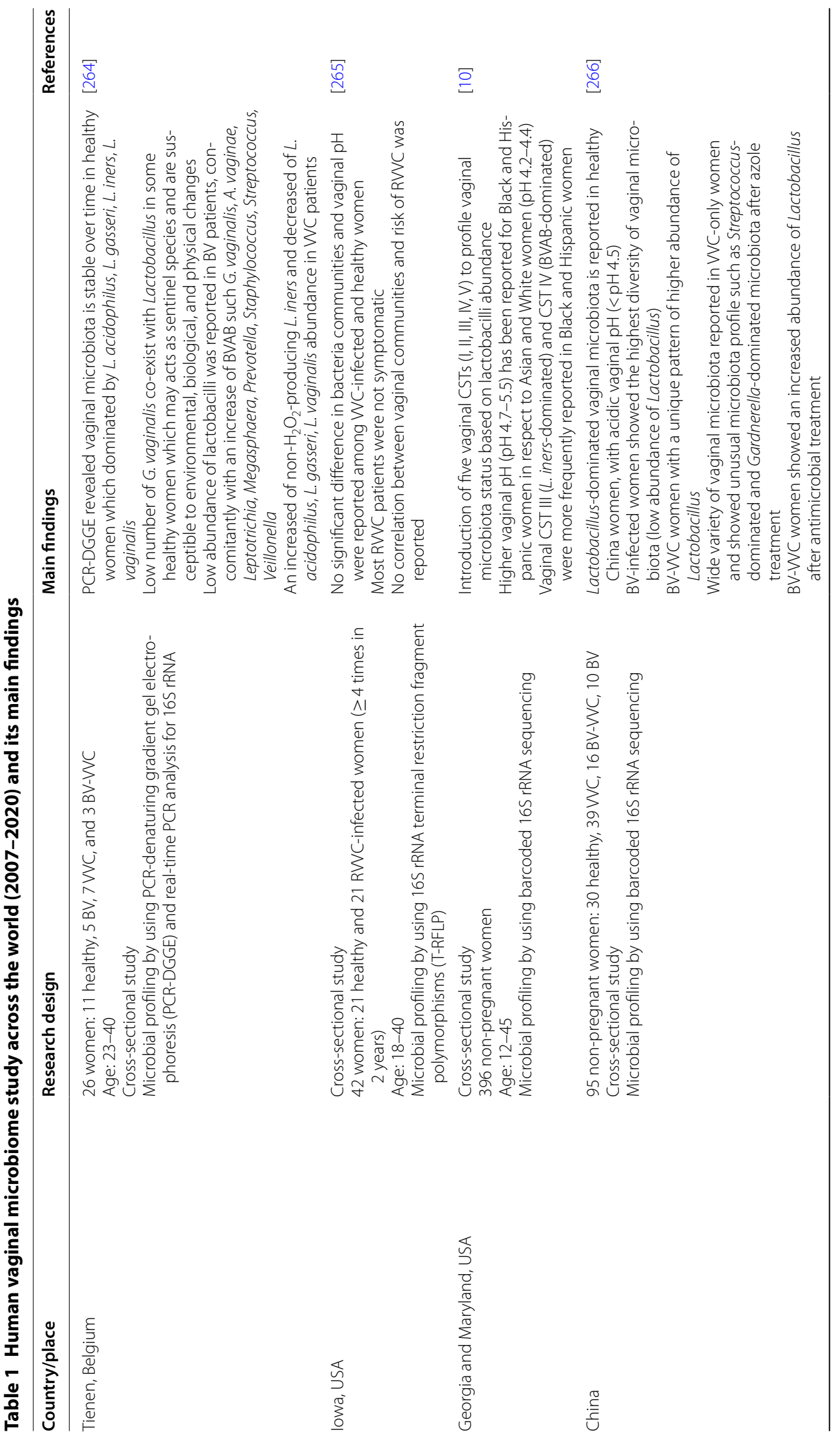


Ghee et al. Micro Cell Fact <wide> <wide> (2020) 19:203

Page 7 of 24

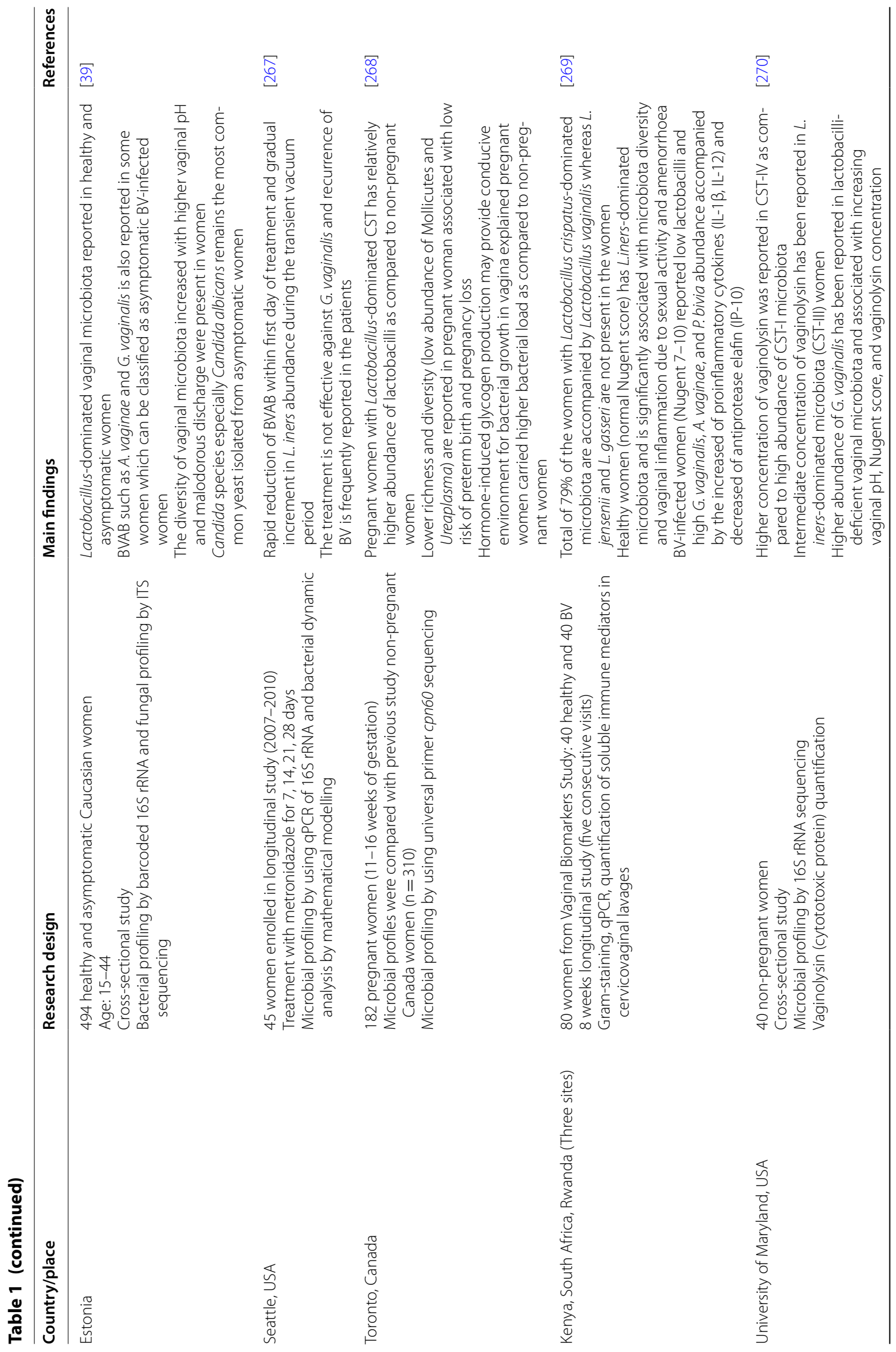


Ghee et al. Micro Cell Fact <wide> <wide> (2020) 19:203

Page 8 of 24

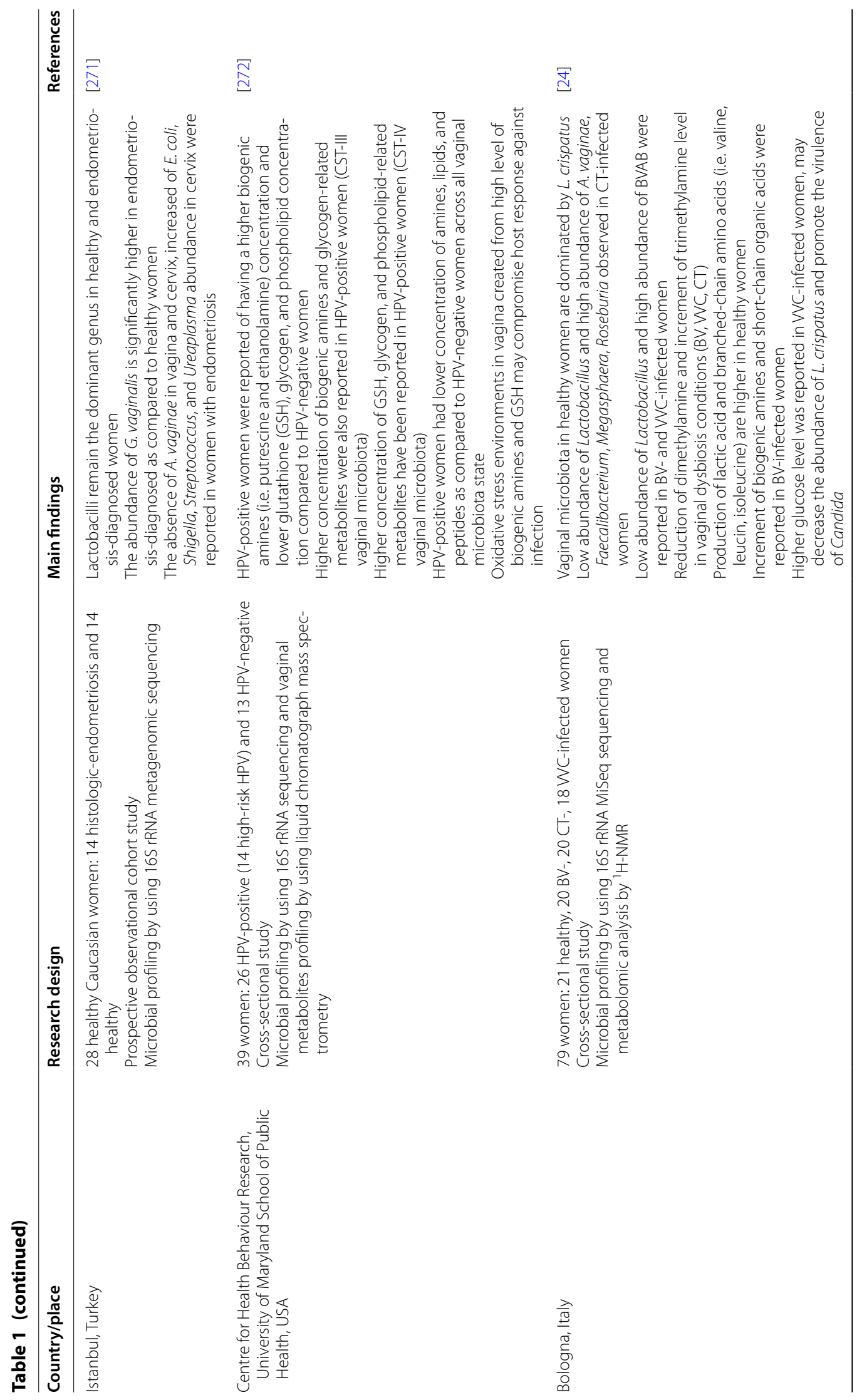




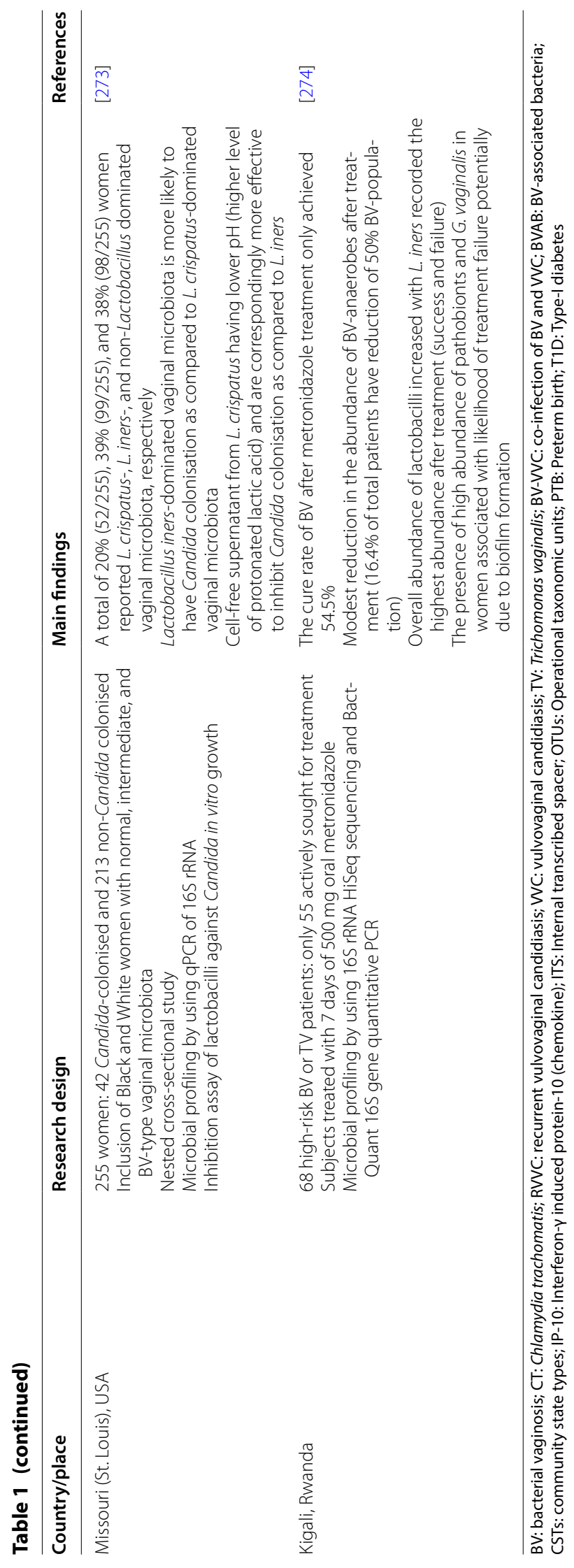


Candida. albicans is the leading vagina coloniser and frequently isolated from vulvovaginal candidiasis (VVC) infected women [72, 73]. Vulvovaginal candidiasis happens in $75 \%$ of women at least once in a lifetime [72], while approximately $5-10 \%$ of women with the primary episode of VVC will develop RVVC (> four episodes annually) [74]. As one of the most common vaginal inhabitants, $C$. albicans has been frequently shown to co-colonise vagina with Lactobacillus [75]. Moreover, the isolation of non C. albicans Candida (NCAC) species such as Candida tropicalis, C. glabrata, C. krusei, C. dubliniensis, and $C$. parapsilosis were frequently observed in RVVC-infected women [76-79]. Non-specific symptoms reported by patients with VVC and recurrent VVC include vulvar erythema, pruritus, dyspareunia, burning sensations, white clumpy discharge, and soreness [72, 80]. Although VVC is not life-threatening, unresolved $\mathrm{VVC}$ affects their quality of life i.e. mental health, social life, sexual relationship, and working life [74, 81].

Candida albicans is a polymorphic yeast that is capable of yeast-to-hyphae morphogenesis under favourable conditions [82, 83]. Some plausible explanations on how C. albicans switches from mere coloniser to pathogen include vaginal dysbiosis, expression of virulence factors (i.e. hyphal and biofilm formation), and production of proteolytic enzymes [i.e. secreted aspartyl proteinases (SAPs)] that resulted in vaginal immune-toxicity [84]. Swidsinski et al. have demonstrated that intraepithelial lesions in VVC patients contained C. albicans hyphae accompanied by co-invasion of $G$. vaginalis and L. iners [85]. This is one the most compelling evidences showing that morphological plasticity that enables yeastto-hyphae formation in C. albicans and the presence of BVAB could cause symptomatic VVC. Furthermore, disruption of vaginal microbiota (e.g. reduction of LAB population) may promote the ability of Candida species to invade vaginal epithelial cells [18]. Following the breach of vaginal epithelial cells, pseudohyphae and hyphae of $C$. albicans induced the NLRP3 inflammasome receptors of the epithelial cells through a cascade activation and ultimately triggered severe vaginal inflammation [86]. Of all the vaginal microbiota and mycobiota studies, C. albicans remains the most described causative agent for VVC [87]. The distinct hallmark of VVC are vaginal dysbiosis and vaginal mucosa inflammation caused by Candida species [85]. On top of that, the changes in vaginal mycobiota is proven to be associated with diabetes, pregnancy, immunodeficiency-allergic rhinitis, and recurrent vulvovaginal candidiasis (RVVC) status [88, 89]. As has been discussed, the microbiota and mycobiota interactions could contribute to VVC development in women through transient or continuous interplay between among them. Exploring these interactions and searching of potential microbial intervention are crucial to potentially prevent and treat VVC in women.

Bacterial vaginosis (BV) is the most common vaginitis among women of childbearing age and is characterised by significant changes in vaginal microbiota composition from a Lactobacillus-dominated to a polymicrobial community $[24,90]$. According to Peebles et al., 23 to $29 \%$ of women population across seven regions were infected with BV and this has caused a massive economic burden of USD 3.7 to 6.1 billion per annum globally [91]. Bacterial vaginosis can be diagnosed by Amsel criteria, Gram staining, Nugent score, and molecular assays [40,92]. It is usually accompanied by a significant number of G. vaginalis, Prevotella species, A. vaginae, Sneathia species, and other BVAB as a result of disrupted vaginal microbiota [93, 94]. Frequently, BV is associated with elevated risk of HIV acquisition, miscarriage, pelvic inflammatory diseases, preterm labour, postpartum endometritis, and STIs acquisition [90, 95-97]. Besides, BV eventually causes significant psychosocial stress on women. Bilardi et al. [98] demonstrated that women with recurrent BV often experience embarrassment, low self-esteem, and frustration in their daily life.

It is conceivable that the production of bacteriocin and lactic acid from Lactobacillus inhibit the over-proliferation of BVAB in the vagina [99]. However, Lactobacillus-dominated vaginal microbiota is displaced by the overgrowth of Gardnerella species and other BVAB when vaginal dysbiosis happens [100]. Recent studies have demonstrated that the synergistic interactions between BVAB such as $G$. vaginalis and $A$. vaginae significantly enhanced the severity of $\mathrm{BV}$ by increasing bacterial burden [101, 102]. Another important feature of BV is polymicrobial biofilm formation mainly by G. vaginalis, while the presence of other co-colonised BVAB was shown to enhance the biofilm thickness of G. vaginalis growth $[85,103-105]$. Several studies have also demonstrated that $\mathrm{BV}$-associated vaginal microbiota with reduced number of Lactobacillus increased the incidences of other STIs [106-108]. Cone [109] inferred that Lactobacillus-dominated microbiota reduces the transmission of STIs by strongly acidifying the vagina milieu and lowering inflammatory cytokines. Multiple studies also consistently showed that the presence of Lactobacillus significantly reduced $C$. trachomatis virulence via lactic acid [54, 110, 111].

Sexually transmitted infections (STIs) such as chlamydia infections (mainly caused by C. trachomatis), gonorrhoea (Neisseria gonorrhoeae), trichomoniasis (Trichomonas vaginalis) and syphilis (Treponema pallidum) often engendered severe forms of cervicitis, urethritis, vaginitis and genital ulceration in women [112-114]. According to World Health Organization (WHO), the 
annual global estimate for STIs was 376.4 million (chlamydia infections: 127.2 million; gonorrhoea: 86.9 million; syphilis: 6.3 million; trichomoniasis: 156.0 million) [112]. Generally, STIs are curable with short regimens of antibiotic treatment. However, STIs can be transmitted to others and cause epidemic if left untreated [115]. These STIs are commonly correlated with high risk of cervical cancer, infertility, preterm labour, and pelvic inflammatory disease in women [114, 116, 117]. Numerous studies have consistently shown that disrupted or BV-associated vaginal microbiota (low-Lactobacillus abundance) increased STIs incidences [106-108, 118-120]. Besides, the occurrence of STIs is associated with high risk of human immunodeficiency virus (HIV) acquisition. Galvin and Cohen [121] have shown that STIs are able to disrupt the mucosal layer and immune homeostasis of vagina, resulted in increased of HIV shedding [121]. At the same time, asymptomatic Chlamydia trachomatis infection is often under-diagnosed and left untreated among infected individuals [122]. A balanced vaginal microbiota that is rich with Lactobacillus is able to modulate vaginal epithelial cell proliferation and D- lactic acid production and subsequently reduced C. trachomatis elemental bodies internalization into epithelial cells [54]. Therefore, these studies highlighted the importance of vagina homeostasis in providing a natural barrier against the vaginal infections.

Vagina also serves as a reservoir for urinary tract infections (UTIs)-causing uropathogens in women [123]. The commonest pathogens that cause UTIs are Escherichia coli, Klebsiella pneumoniae, Staphylococcus epidermidis, Streptococcus agalactiae (group B Streptococcus), Enterococcus faecalis, Proteus mirabilis, and Pseudomonas aeruginosa [124-126]. While UTIs are curable by antibiotics, severe complications including pyelonephritis, haematuria, and chronic kidney disease (CKD) can cause permanent kidney damage [127, 128]. Studies have shown that pathogens such as Gardnerella, Prevotella, and Ureaplasma potentially ascended from vaginal tract before causing infection in the urinary tract via the urethra and urinary bladder [129-131]. Vaginal dysbiosis has been shown to increase the risk of UTIs acquisition as compared to Lactobacillus-dominated vaginal microbiota $[123,132]$. In fact, exposure of mice vagina to G. vaginalis triggered the recurrent UTIs that are caused by $E$. coli [133]. Thus, maintaining vaginal homeostasis could suppress the pathogenesis of uropathogens in the urinary bladder. Another serious illness that torment women of child-bearing age is toxic shock syndrome (TSS), which is associated with the colonisation of TSS toxin (TSST-1) producing S. aureus in vagina [134]. It is well established that TSST-1 is produced in neutral $\mathrm{pH}$ (i.e. $\mathrm{pH}$ 6.5-7.0), a condition which is frequently reported in diseased-state vagina [135]. Multiple studies have shown that usage of menstrual cups, tampons, and contraceptive diaphragms can disrupt Lactobacillus-dominated vaginal microbiota and enhance the growth of $S$. aureus and production of TSST-1 [136-138]. The over-production of TSST-1 can lead to severe complications such as organ failure, systemic inflammation, and death in women [139]. In summary, vaginal dysbiosis can cause the loss of $L A B$ protective effect in vagina and increase the risk of uropathogens ascending from vagina that eventually lead to UTIs.

A well balanced and disrupted vaginal microbiota essentially are significantly associated with healthy- and diseased-state vagina. Apart from host predisposition to BV, STIs, VVC, and UTIs, disruption of vaginal microbiota actively deprives the beneficial functions of Lactobacillus against opportunistic pathogens in vagina. Further exploration with a holistic study design such as diverse populations, ethnicity, and geographical area can potentially lead to development of predictive marker for diagnosis of disrupted vaginal microbiota. The complementary approach in improving and restoring vaginal microbiota to non-diseased status is thereafter needed by using biotherapeutic agents such as Lactobacillus to reduce risks of these vaginal infections.

\section{Potential of Lactobacillus in keeping vaginal pathogens commensals}

Lactic acid bacteria are representative microorganisms from a diverse group of bacteria that are characterised as Gram-positive, microaerophilic, acid-tolerant, non-sporulating, and capable of lactic acid production [140, 141]. The prevailing genera of $\mathrm{LAB}$ that are used as probiotics are Lactobacillus, Bifidobacterium, Streptococcus, Enterococcus, and Pediococcus [142, 143]. The GRAS status of lactic acid by Food and Drug Administration (FDA) has been extensively utilised in food, dairy, and pharmaceutical industries [144, 145]. For instance, Lactobacillus delbrueckii subsp. bulgaricus has been employed along with Streptococcus thermophilus as starter culture in manufacturing yoghurts and cheeses [146, 147]. According to Reid et al., the administration of probiotic lactobacilli in adequate amounts is able to confer health benefits to host by restoring microbial and host immune homeostasis [148].

An increasing number of studies have elucidated the fundamental probiotic effects of Lactobacillus against pathogens present in the GI tract, oral cavity, vagina, and epidermal layer [149-152]. Lactobacillus acidophilus KS400 has been proven to produce bacteriocin through fermentation and inhibited the growth of urogenital pathogens such as G. vaginalis, S. agalactiae, and P. aeruginosa [153]. Additionally, bacteriocin from vaginal $L$. 
rhamnosus (Lactocin 160) was able to produce transient pores on the cytoplasmic membrane of $G$. vaginalis by collapsing the chemiosmotic potential of the pathogen [154]. Multiple studies have also shown that aerobic vaginitis (AV)-causing pathogens such as E. coli, E. faecalis, $S$. aureus, $S$. epidermidis, and $S$. agalactiae commonly reside in the vagina and induce inflammatory vaginitis [155, 156]. Prolonged treatment of vaginitis with antimicrobial drugs can result in development of drug resistance [157, 158]. Thus, the probiotic lactobacilli-based approach as an alternative to the conventional antimicrobial treatment is being extensively studied. According to Bertuccini et al. [159], L. rhamnosus HN001 and L. acidophilus GLA-14 were able to significantly inhibit the growth of $G$. vaginalis, $A$. vaginae, $S$. aureus, and $E$. coli. In an attempt to elucidate the effect of Lactobacillus introduction in vaginal microbiota, a study has shown that oral administration of mixed L. acidophilus La-14 and L. rhamnosus HN001 have significantly increased vaginal $L$. rhamnosus and L. acidophilus abundance starting at day 7 and 14 , respectively [160]. In a similar study, orally-administered of probiotic formulations (L. acidophilus PBS066 and $L$. reuteri $\mathrm{PBS} 072$ ) and (L. plantarum PBS067, L. rhamnosus PBS070 and B. lactis PBS075) significantly increased the abundance of lactobacilli and bifidobacteria in vagina, starting at day 7 as compared to placebo-control group [161]. Apart from that, it has been reported that culture supernatants from multiple lactobacilli strains inhibited C. albicans significantly by suppressing the expression of adhesion and hyphae-related genes [162]. Ironically, genes related to SAPs were not affected, thus suggests the importance of these proteinases in the survival of C. albicans within Lactobacillus-dominated vagina. The anti-Candida activity observed was partially attributed to the presence of bacteriocin, hydrogen peroxide, and lactic acid [162]. In addition, $\mathrm{Li}$ et al. implicated that both L. crispatus and L. delbrueckii were able to inhibit 60 to $70 \%$ of C. albicans in VVC Sprague-Dawley rat model as compared to non-treated control [163].

Lactobacillus interventions have been demonstrated to be beneficial in co-treatment with antimicrobials drugs and prevention of recurrent infections. One of the studies that adopted this approach showed that oral coadministration of multispecies-lactobacilli (L. fermentum 57A, L. gasseri 57C, and L. plantarum 57B) with metronidazole, lengthened the relapse of $\mathrm{BV}(51 \%)$ and $\mathrm{AV}$ (71\%) significantly, and maintained the acidity of vaginal $\mathrm{pH}$ [164]. It is believed that the bile acid-tolerant Lactobacillus were able to increase the abundances of lactobacilli in intestinal before migrating to vagina cavity [148, 165]. Nevertheless, the exact mechanism of how oral probiotics travel and dominate in vagina remains debatable [166, 167]. Intravaginal administration of probiotics was also invented to restore the disrupted vaginal microbiota. Bohbot et al. [168] reported that 28 days intravaginal administration of lyophilised L. crispatus IP 174178 was able to reduce the recurrence rate $(20.5 \%)$ and prolonged the time for BV recurrence (28\%) as compared to placebo-control group. Moreover, vaginal tablet consists of L. fermentum LF15 and L. plantarum LP01 restored the acidity of vaginal $\mathrm{pH}$ and the threshold level of Nugent score to below 7 (balanced vaginal microbiota) through the inhibition of G. vaginalis [169]. Lactobacillus rhamnosus BMX 54 also has been clinically tested on $\mathrm{BV}$ patients and has been shown to be able to restore vaginal microbiota to balanced state following three months administration [170]. In addition, L. rhamnosus BMX 54 also showed its potential to be used as adjuvant treatment in reshaping vaginal microbiota and by reducing $B V$ recurrence after six to nine months of treatment [171]. Recent evidence showed that intermittent application of vaginal capsule (containing Lactobacillus acidophilus W70, Lactobacillus brevis W63, Lactobacillus helveticus W74, Lactobacillus plantarum W21, Lactobacillus salivarius W24, and Bifidobacterium bifidum W28) restored Lactobacillus-dominated vaginal microbiota and significantly reduced risk of BV incidence by 2.8-fold as compared to non-treated control group (10.18 per person-year) [172]. Meanwhile, the usage of lactobacilli could also reduce the rate of VVC recurrence. For instance, oral co-administration of clotrimazole and oral capsule (containing L. acidophilus GLA-14 and L. rhamnosus HN001) with bovine lactoferrin RCX were shown to significantly reduce VVC recurrence by $58.4 \%$ and $70.8 \%$, respectively at three and six months as compared to non-lactobacilli administration control group [173]. It is imperative that the restoration of vaginal microbiota could prevent various vaginal infections and the rate of its recurrence. According to Xie et al. [174], there are insufficient shreds of evidence to recommend the usage of only probiotics in countering VVC and BV as compared to conventional drugs treatment.

A eubiotic vaginal ecosystem that is dominated by Lactobacillus has the potential to protect host against HIV and STIs [20, 175]. According to McClelland et al., high abundance of BVAB was associated with the risk of HIV acquisition in women [108], possibly due to increased vaginal $\mathrm{pH}$ and production of an enzyme that inhibits anti-HIV immunity [176]. Several studies have been carried out to determine the potential of Lactobacillus in suppressing BV-associated bacteria and HIV transmission in vitro and ex vivo $[177,178]$. Culture supernatant produced by vaginal-isolated Lactobacillus strain has been shown to be able to suppress HIV-type 1 infection in human cervicovaginal tissue [178]. In this study, the Lactobacillus culture supernatant has been proven to be 
viricidal and it helps in reducing virion dissemination in the host [178]. Besides, heat-killed L. gasseri also demonstrated high inhibitory activity (81.5\%) against HIV-1 strain X4 infectivity on TZM-bl cellosaurus cell line [179]. In a similar study, L. casei $393\left(1 \times 10^{4}\right.$ cells $\left./ \mathrm{mL}\right)$ was able to inhibit HIV-1 pseudoviruses (AD8, DH12, and LA1), ranged from 60 to $70 \%$ after $30 \mathrm{~min}$ of coincubation [180]. Recently, Palomino et al. found that the inhibitory effect of Lactobacillus against HIV-1 infection is associated with the presence of extracellular vesicles, which inhibit the HIV adhesion and viral entry to target cells [181]. Prospective studies have consistently suggested that disrupted vaginal microbiota increased the risk of HIV acquisition among women [23]. Future studies should prioritise the elucidation of mechanisms that explain the vaginal dysbiosis and HIV acquisition, and the discovery of probiotic lactobacilli as effective intervention for HIV prevention.

Collectively, Lactobacillus shows a promising effect in prevention of vaginal infection such as BV and VVC. The complementary approach by using probiotic lactobacilli to redress vaginal microbiota imbalance is in dire need to reduce the utilisation of antimicrobial drugs. More clinical trials on the efficacy of probiotic lactobacilli against vaginal infection should be conducted to address the heterogeneity of probiotic effectiveness.

\section{Potential of surface-active molecules (SAMs) from Lactobacillus}

Many potential mechanisms have been proposed to be responsible for the probiotic effects of lactobacilli, these include competition for colonisation, modulation of host immune response, cross-feeding of beneficial microbiota, production and secretion of lactase, bile salt hydrolase, organic acids and antimicrobial compounds [Reviewed in $[182,183]]$. The probiotic characteristics of lactobacilli associated with the host-Lactobacillus interaction is reckoned to be contributed by the Lactobacillus surface-active molecules (SAMs) [184]. Lactobacillus SAMs that have been reported to support probiotic actions are peptidoglycan (PG), bacterial polysaccharides, biosurfactants (BS), and teichoic acids (TA) $[185,186]$. The core SAMs that are shared among LAB includes lipoteichoic acid, polysaccharides, surface layer associated proteins (SLAPs), mucin-binding proteins (MUBs), and fibronectin-binding proteins [187]. This core SAMs govern the host-microorganism interactions upon LAB adhesion. In fact, it has been shown that SAMs mediate the host physiological responses directly via direct adherence to the epithelial cells and pattern recognition receptors (PRRs) on mucosa layer [187]. As Lactobacillus SAMs could be important for the regulation of host-microorganism interaction in vagina, research on these SAMs should be focused to a greater extent in order to produce novel SAMs-based treatment, potentially as an alternative to currently available therapeutic options.

\section{Peptidoglycan (PG)}

Peptidoglycan (PG) is a biopolymer which comprises glycan strands connected by $\mathrm{N}$-acetyl-glucosamine (GlcNAc) and $N$-acetylmuramic acid (MurNAc) side chains that form the cell surface of Gram-positive bacteria such as Lactobacillus and bifidobacteria [188, 189]. Generally, the cytoplasmic membrane of Lactobacillus is surrounded by PG network and other biopolymers, namely teichoic acids (TA), S-layer proteins, and polysaccharides $[189,190]$.

In general, STI pathogen such as N. gonorrhoeae is able to suppress the host Th-1-driven adaptive immune response by inhibiting the production of interleukin-12 (IL-12) [191]. In view of that, intravaginal administration of microencapsulated IL-12 was able to reverse the immunosuppression in mice and also promotes the clearance of gonorrhoea infection [191]. At the same time, Lactobacillus PG demonstrates outstanding immunomodulatory activity in improving host innate immune responses. For instance, Lactobacillus casei PG was able to induce the production of IL-12 by mice peritoneal macrophages through toll-like receptors 2 (TLR2) and nucleotide-binding oligomerization domain 2 (NOD2) [192]. Moreover, L. plantarum CAU1055 PG demonstrated the ability to ameliorate nitric oxide-induced inflammation in RAW264.7 murine macrophages through the inhibition of nitric oxide (NO) synthase, cyclooxygenase-2 (COX-2), and cytokines (TNF- $\alpha$ and interleukin-6) [193]. In a similar study, PG derived from $L$. acidophilus has been reported to significantly reduce the NO synthase and COX-2 levels on LPS-induced RAW 264.7 macrophages as well [194]. On top of that, vaginal isolate $L$. crispatus PG was able to stimulate the expression of CD207 of Langerhans cells (antigenpresenting dendritic cells on vagina) and significantly reduced the expression of receptors for HIV entry [195]. The balance of vaginal microbiota and immune system in vaginal epithelial cells are crucial to prevent vaginal infection [196]. The potential effect of PG in modulating immune homeostasis could effectively assist in the maintenance of healthy vaginal ecosystem for women's health and well-being. Apart from the reported immunomodulatory activity, L. brevis PG also exhibited strong antiviral activity against genital herpes simplex virus-2 (HSV-2) [197]. According to Mastromarino et al. [197], the antiviral activity of L. brevis PG was unaffected by heat- and protease-treatment, and it still inhibited HSV-2 replication significantly in a concentration-dependent manner. 


\section{Lipoteichoic acid (LTA)}

Lactobacillus PG is usually decorated with teichoic acids (TA) or lipoteichoic acids (LTA) [198]. Lipoteichoic acids are generated from the polymerisation of glycerol-phosphate and are bound to the cytoplasmic membrane [199, 200]. Together with other SAMs, LTA modulates the host pattern recognition receptors (PPRs) and several signalling pathways of host that are accounted for the probiotic and anti-pathogen effect of Lactobacillus [185]. The eradication of polymicrobial biofilms in human vagina is one of the strategies that can be used to impede bacterial virulence and prevent the onset of BV [201]. Lactobacillus plantarum LTA hampered the formation of $S$. mutans biofilms on hydroxyapatite discs via the attenuation of the sucrose decomposition [35]. Moreover, $L$. plantarum LTA significantly inhibited E. faecalis biofilm formation and preformed biofilm on human dentin slices suggesting that LTA can be employed as a preventive and therapeutic measures for E. faecalis infection [202]. Also, L. plantarum LTA inhibited polymicrobial biofilm consists of Actinomyces naeslundii, Lactobacillus salivarius, E. faecalis, and S. mutans on dentin slices [203]. Other than anti-adhesion and anti-biofilm properties, Lactobacillus LTA also possesses immunomodulatory activity. For instance, Lactobacillus johnsonii La1 and Lactobacillus acidophilus La10 LTAs ameliorated the overstimulation of pro-inflammatory cytokines production such as TNF- $\alpha$, IL-8, and interleukin-5 (ENA-78) in intestinal epithelial cells, in the presence of lipopolysaccharides (LPS) or Gram-negative bacteria [204]. According to Ahn et al., LTA from L. plantarum $\mathrm{K} 8$ also modulated inflammatory cytokines (TNF- $\alpha$ and IL-10) production in LPS-challenged THP-1 cells [205]. Patients with BV, sexually-transmitted diseases are often associated with overstimulation of pro-inflammatory cytokines and neutrophils recruitment to vagina mucosa surface $[119,206]$. Thus, the immunomodulatory activity of lactobacilli LTA could dampen the overstimulation and vaginal inflammation caused by pathogens.

\section{Bacterial polysaccharides}

Bacteria form tightly-linked polymers on the cell surface and release them to the environment as exopolysaccharides (EPS) (loosely unattached slime) [31, 207]. By exploiting the surface polysaccharides in mimicking host's glycan structure, pathogenic bacteria are able to evade the host immune system during colonisation [208]. Generally, EPS secreted by bacteria are crucial for the adhesion and cellular recognition during hostmicroorganism interaction [209]. Exopolysaccharides are high molecular weight, biodegradable carbohydrate polymers and are designated into homopolysaccharides or heteropolysaccharides based on their monosaccharides constituents [Reviewed in [210-212]]. Exopolysaccharides from LAB have attained substantial attention in the past decade due to their capability to inhibit bacterial toxins produced by Bacillus cereus [213]. The production of Lactobacillus EPS is regulated by the culture conditions and nutrient compositions during fermentation $[214,215]$. For instance, the production of L. rhamnosus EPS was significantly increased by 40 to $50 \%$ following $48 \mathrm{~h}$ of co-fermentation with $S$. cerevisiae, owing to the upregulation of EPS operons expression that enhanced amino acid biosynthesis, carbohydrate metabolism, and fatty acid metabolisms [216]. Besides, the production of Lactobacillus pentosus EPS was strongly affected by different carbon sources used for the fermentation process such as glucose which enhance the viscosity of EPS for a better thickening effect in milk production [217]. Similar study also reported that higher production of L. plantarum EPS was observed in de Man, Rogosa and Sharpe (MRS) medium supplemented with glucose as carbon source [218]. Different carbon source of culture medium also significantly influences the functional activity of Lactobacillus EPS. As proof, MRS supplemented with sucrose significantly increased the EPS production of L. plantarum LPC-1 [219]. However, higher antioxidant activity was reported in L. plantarum LPC-1 when glucose is used as the carbon sources as compared to sucrose [219]. Collectively, the two concomitant factors that affect the EPS production (Lactobacillus strains and carbon source) resulted in distinct rheological properties of EPS which can influence the EPS functional activity.

The unique physiochemical properties of Lactobacillus EPS has the potential to confer health benefits to human as it has been reported to possess anti-atherosclerotic, anticancer, antioxidant, antiviral, anti-yeast, immunomodulatory, and prebiotic properties [220-224]. Human defensin-2 is an antimicrobial peptide that is secreted by the host epithelial cells which helps in the regulation of inflammation and microbiota function in vagina tract [225]. Correspondingly, Lactobacillus crispatus L1 EPS strongly enhanced the ability of vaginal epithelial VK2 cell to produce human defensin-2 protein (candidacidal effect) and it also reduced the adhesion of C. albicans (48\%) by competitive exclusion [226]. Likewise, the competitive exclusion was observed between L. rhamnosus GG EPS and multiple Candida species, as demonstrated by the significant reduction of the adhesion of C. albicans (30\%) and C. glabrata (25\%) on VK2 and human bronchial Calu-3 cell line, respectively [224]. It is perceivable that the yeast-to-hyphae switching is crucial for C. albicans pathogenesis and immunopathogenesis [227]. A study conducted by Allonsius et al. [224] reported that EPS from L. rhamnosus GG 
inhibited hyphal formation in C. albicans by $40 \%$ further corroborates the potential anti-Candida properties of Lactobacillus EPS. Bacterial vaginosis is characterised by the presence of polymicrobial biofilm on the vaginal epithelia [228]. Lactobacillus plantarum WLPL04 EPS was reported to significantly reduce the adhesion of $E$. coli, P. aeruginosa, S. aureus, and Salmonella typhimurium on HT-29 cell line [33], which make it a potential antibiofilm agent that is worth to be developed for better BV management.

The occurrence of BV has been associated to the formation of high oxidative stress (e.g. high level of malondialdehyde (MDA) production and low superoxide dismutase (SOD) activity) and degradation of mucin in the vaginal milieu [229, 230]. Thus, it is crucial that high antioxidant capacity of vaginal epithelium may reduce the oxidative stress formed during the BV infection and enhance the vaginal immune system against pathogens. Lactobacillus plantarum C88 EPS was also shown to demonstrate high antioxidant effects by reducing MDA level and raising SOD activity in a dose dependent manner [231]. Besides, pure EPS extracted from L. helveticus KLDS1.8701 significantly improved the antioxidant activity of mice liver towards oxidative stress through the reduction of SOD activity [232]. Apart from antioxidant capability, Lactobacillus EPS also demonstrated the ability to ameliorate degraded mucin barrier in cell. For instance, L. plantarum EPS promotes mucosal healing and protection by increasing the mucin MUC2 gene expression, tight junction protein expression and goblet cell differentiation in mouse colon [233, 234]. In fact, mucin has been shown to prevent the adhesion of vaginal pathogens and promotes the adhesion of LAB on epithelial cells [25].

The prebiotic properties of EPS have been actively explored. Generally, prebiotics can be retrieved from natural sources to serve as an energy source for epithelial cells and stimulate the growth of beneficial bacteria in the gut [142]. The general requirements for a compound to be considered as "prebiotic" include the ability to withstand gastrointestinal enzymes and absorption in small intestines, as well as the capability to stimulate the metabolic activities of beneficial bacteria via fermentation [212]. Sims et al. [235] have shown that the utilisation of prebiotics oligosaccharides such as $\beta$-glucan, inulin, and fructo-oligosaccharides stimulated the growth of probiotic $L A B$, suggesting the combination of prebiotic and probiotic can offer health benefits to host. The glucan EPS of Lactobacillus brevis ED25 was demonstrated to increase the shelf life of probiotic L. rhamnosus GG in food and also elevated the viability of L. rhamnosus GG [236]. Polysaccharides from probiotic EPS were suggested to play a role in elevating the abundance of normal flora in intestinal surface through bacteria cross-talk
[237]. Extrapolation can be made that similar interaction could be observed in the beneficial bacteria within the vaginal milieu.

\section{Biosurfactant (BS)}

Biosurfactants (BS), also known as bio-emulsifier are amphipathic active compounds mostly synthesised by microorganisms [238]. These amphipathic molecules have granted microorganisms the ability to reduce the surface and interfacial tension between aqueous solution through emulsion [239]. Biological BS can be categorised into low molecular weight surfactant (e.g. glycolipids and lipopeptides) and high molecular weight surfactant (e.g. glycoprotein complexes, lipopolysaccharides, and lipoproteins) [240]. Besides its important role in agriculture, animal feeds, cosmetic, food and oil industries, BS has recently drawn the attention of scientific community due to its bioremediation potential [241, 242]. However, the functional activity of Lactobacillus BS remains understudied [240]. Mouafo et al. has shown that the production of BS from Lactobacillus is dependent on the choice of fermentative carbon sources. Carbon sources originated from sugarcane and glycerol increased the yield of BS effectively compared to MRS broth [243].

Biosurfactants have been reported to exhibit antiadhesion and antimicrobial characteristics by altering the surface chemistry for microbial attachment [182]. Sophorolipid is a type of glycolipid BS commonly produced by non-pathogenic yeast Starmerella bombicola [244]. This compound has been proven to be able to inhibit the formation of $C$. albicans biofilm, as well as disrupt the preformed C. albicans biofilms [244]. Astonishingly, Haque et al. [244] also found that the combination of sophorolipid and antifungal drugs is highly effective in inhibiting $C$. albicans as shown by the absence of $C$. albicans hyphae and biofilm complex networks after treatment. As for BS produced by Lactobacillus, it was recently reported that BS from $L$. acidophilus ATCC 4356, Lactobacillus debrueckii ATCC 9645, and Lactobacillus paracasei 11 significantly reduced the biofilm formation of vaginal pathogen C. albicans by 40 to $50 \%$ [245]. Also, BS derived from L. brevis CV8LAC was reported to effectively inhibit $24 \mathrm{~h}-, 48 \mathrm{~h}-$, and $72 \mathrm{~h}-C$. albicans biofilm formation on silicone elastomeric discs ( $90 \%)$ [246]. Other than inhibition on C. albicans biofilm, BS from L. jensenii $\mathrm{P}_{6 \mathrm{~A}}$ and L. gasseri $\mathrm{P}_{65}$ also exhibited potent antimicrobial and anti-biofilm activities against multiple urogenital pathogens such as E. coli, Klebsiella pneumoniae, Staphylococcus saprophyticus, and Enterobacter aerogenes [247]. Besides, crude L. paracasei BS inhibited Streptococcus pyogenes, Staphylococcus epidermidis, E. coli, P. aeruginosa, S. aureus, and S. agalactiae [248]. Gudiña et al. [248] found that L. paracasei 
$\mathrm{BS}$ is still highly stable following $\mathrm{pH}$ alkalisation $(\mathrm{pH} 6$ to 10 ) and heat treatment $\left(60^{\circ} \mathrm{C}\right)$. On top of that, the extraction of crude $L$. paracasei $\mathrm{BS}$ via acidic preparation also greatly enhanced the antimicrobial activity [248]. Multiple studies were also performed to identify the effects of lactobacilli BS against other vaginal and uropathogens. According to Spurbeck and Arvidson [249], L. gasseri 33323 BS demonstrated anti-adhesion activity against sexually-transmitted pathogen Neisseria gonorrhoeae through the blocking of fibronectin, an extracellular matrix component on the epithelial cells. Biosurfactant from $L$. crispatus also significantly inhibited $N$. gonnorrhoeae growth $(>50 \%)$ following incubation at two timepoints, i.e. $7 \mathrm{~min}$ and $60 \mathrm{~min}$ [250]. Jiang et al. have reported that the mechanism involved in the anti-adhesion activity of L. helveticus 27170 BS against S. aureus was associated with the disruption of autoinducer-2 signaling (quorum sensing molecule) in S. aureus [251]. Besides, Satpute et al. revealed that $L$. acidophilus BS was able to reduce E. coli, S. aureus, P. vulgaris, B. subtilis, and $P$. putida biofilms on medical implant polydimethyl siloxane (PDMS) surface through anti-adhesion mechanism [252]. Recently, BS from L. crispatus BC1 also demonstrated significant in vitro anti-adhesion activity against $C$. albicans through exclusion mechanism on human cervical cancer HeLa cell line and in vivo immunomodulatory activity by reducing the leukocyte influx (i.e. prevent mucosal damage) caused by $C$. albicans in mice [253]. Based on these findings, it is conceivable that the mechanism of action of Lactobacillus BS involves adhesion interruption rather than killing of the invading pathogens.

\section{Challenges of Lactobacillus SAMs applications}

Although there are substantial evidences that Lactobacillus SAMs could benefit human, implementation their use still remain obscure and challenging. One such challenge would be the cost required for their production. As their extraction is often hindered by low yields, optimisation of growth medium composition and extraction methods are essential [210, 215, 254]. In addition, other factors such as type of carbon sources and $\mathrm{pH}$ also significantly influence EPS structure and yields [255]. Therefore, mass production of SAMs often requires extra efforts that could be time-consuming and cost-ineffective. Additionally, the adoption of SAMs in large-scale industrialisation remain elusive due to the nature of SAMs structure fluctuation according to the medium composition. In an attempt to lower the high production cost of fermentation to produce lactobacilli SAMs, carbon-rich agricultural wastes such as bran, sugar cane and beet molasses could be employed as an alternative culture medium [256]. The utilisation of low-cost agricultural waste-based media potentially reduce the high cost inputs during largescale fermentation process and meet the high market demand of lactobacilli SAMs in the future. Moreover, the cost of lactobacilli SAMs production can be reduced by determining the most economical culture medium composition for the maximum yield [215]. For instance, economic modelling via formula adjustment and production possibility curve (PPC) were performed to assess the carbon source for optimal culture medium composition and optimal productivity set (OPS) of $L$. acidophilus EPS production [215]. According to Lin et al. [215], the total cost production of $L$. acidophilus EPS by using MRS-nutrient broth culture medium was able to reduce by $30 \%$ (USD $7.5 / \mathrm{kg} / \mathrm{L}$ culture) as compared to MRS only (USD 11.0/kg/L culture). Apart from that, statistical design is also one of the salient approaches that can be utilised to optimise media composition for the maximum yield of lactobacilli SAMs. The most widely used statistical designs for the optimisation of media suitable for SAMs (e.g. biosurfactant) production are factorial design and Response Surface Methodologies (RSM) [257]. In fact, factorial design such as Plackett-Burman Design (PBD) has been employed to optimise the cost-effective culture medium for EPS production in L. rhamnosus by modifying single- and multi-factor-at-a-time (i.e. type of carbon and nitrogen sources) through statistical modelling [254]. Meanwhile, RSM such as Central Composite Design (CCD) is a critically acclaimed statistical design that has been used to analyse and evaluate the growth kinetic parameters for the increased EPS production of L. plantarum [218]. In brief, the use of economical modelling and statistical designs permit the selection of crucial formulations that influence the production of lactobacilli SAMs that could ultimately lower the overall cost of SAMs production. Besides, the recovery of SAMs from Lactobacillus could be improved by using genetically engineered SAMs-producing Lactobacillus strain. For instance, Li et al. [258] have shown that the NADH metabolic pathway needed for EPS production can be rerouted to increase the amount of $L$. casei LC2W EPS by $46 \%$. However, the usage of genetically engineered lactobacilli may engender safety concerns among public. The potential risk and safety issue can be addressed by careful experimental inspection before the administration [259]. While a plethora of studies have been carried out in vitro, in vivo testing of Lactobacillus SAMs effectiveness to prevent vaginal infection remains understudied. Nonetheless, allogeneic immune response makes the reconstitution of healthy vaginal microbiota to a Lactobacillus-dominated microenvironment challenging. Thus, a personalized approach in treating vaginal infections is required to proclaim the beneficial effect of $\mathrm{Lac}$ tobacillus [260]. Besides, high recurrent rate of vaginal 
infections often suggests the futility of antimicrobial drugs in long-term treatment. With the use of lactobacilli and potentially its derivatives (i.e. SAMs), restoration of a balanced vaginal microbiota could be achieved. Future investigations should focus on creating an economicallyfeasible approach for large-scale generation of Lactobacillus SAMs in order to solve the production bottleneck and to be used as the potential treatment for human vaginal infections.

\section{Conclusions}

The presence of vaginal microbiota and mycobiota in human vagina shape the healthy and diseased state of vaginal ecosystem. Over the past decade, vaginal microbiome profiling has been extensively studied. Numerous studies reported that healthy vaginal CSTs are usually dominated by LAB (i.e. Lactobacillus), low diversity of anaerobic bacteria, and a balanced vaginal immune system (e.g. pro-inflammatory and anti-inflammatory cytokines). The host predisposing and genetic factors have been proven to alter vaginal microbial composition. Thus, disrupted vaginal ecosystem often results in diseased state of CST and symptomatic vaginitis. Meanwhile, Lactobacillus have shown to possess potential health benefits in immunomodulation and restoration of healthy microflora in gut and vagina. Despite rare Lactobacillus bacteraemia reported in immunocompromised patients, their beneficial effects in reducing recurrence rate of vaginal infection and preventing vaginally-acquired infections are well-founded. Therefore, the development of other potential treatments from probiotics should be invested to position the promising benefits of probiotics in immunocompromised patients.

The utilisation of Lactobacillus as prophylaxis appeared to be a long-term beneficial approach. As discussed in this review, lactobacilli derivatives (i.e. SAMs) could be utilised as a prevention for vaginal infection via restoration of indigenous microbiota and their anti-biofilm capability. The successful restoration of Lactobacillusdominated composition in BV patients was reported with lower recurrence rate along with the significant decrease in BV-related bacteria such as Gardnerella, Prevotella, Megasphaera, Coriobacteriaceae, and Atopobium [261]. The beneficial effects of lactobacilli SAMs which act against vaginal pathogens include anti-biofilm, antioxidant, antiviral, pathogen-inhibition, and immunomodulation are proposed to directly involved in the interaction between human host and vaginal microbiota. Considering the ability of Lactobacillus SAMs to significantly inhibit the in vitro growth of vaginal pathogens, further studies should be directed on their mechanisms in in vivo model. This will be a valuable tool to facilitate the understanding of role of lactobacilli and derivatives in modulating mucosal barrier of vagina against invading pathogens. The new evidence in the understanding of potential lactobacilli SAMs and their respective mechanistic knowledge will greatly promote the development of prebiotics and antimicrobial agents, aiming on the prevention and treatment of vaginal diseases such as BV, STIs and VVC.

\begin{abstract}
Abbreviations
AV: Aerobic vaginitis; BS: Biosurfactant; BV: Bacterial vaginosis; BVAB: Bacterial vaginosis-associated bacteria; CKD: Chronic kidney disease; COX-2: Cyclooxygenase-2; CST(s): Community state type(s); CT: Chlamydia trachomatis; ENA78: Interleukin-5; EPS: Exopolysaccharides; FMT: Faecal microbiota transplantation; GICNAc: N-acetyl-glucosamine; GRAS: Generally recognised as safe; HIV: Human immunodeficiency virus; HMP: Human Microbiome Project; HPV: Human papillomavirus; HSV-2: Herpes simplex virus-2; HMP: Integrative HMP; IL-12: Interleukin-12; LAB: Lactic acid bacteria; LPS: Lipopolysaccharides; LTA: Lipoteichoic acid; MDA: Malondialdehyde; MRS: de Man, Rogosa and Sharpe; MUBs: Mucin-binding proteins; MurNAc: $\mathrm{N}$-acetylmuramic acid; $\mathrm{NIH}$ : National Institutes of Health; NO: Nitric oxide; NOD2: Nucleotide-binding oligomerization domain 2; OTUs: Operational taxonomic units; PDMS: Polydimethyl siloxane; PG: Peptidoglycan; PRRs: Pattern recognition receptors; RVVC: Recurrent VVC; SAPs: Secreted aspartyl proteinases; SAMs: Surface-active molecules; SLAPs: Surface layer associated proteins; SOD: Superoxide dismutase; STIs: Sexually transmitted infections; TA: Teichoic acid; TLR2: Toll-like receptor 2; TNF-a: Tumour necrosis factor-a; TSS: Toxic shock syndrome; TSST-1:TSS toxin; UTIs: Urinary tract infections; VMT: Vaginal microbiota transplantation; VVC: Vulvovaginal candidiasis.
\end{abstract}

\section{Acknowledgements}

Not applicable.

\section{Authors' contributions}

WJYC, SYC, and LTLT reviewed the literature and co-wrote the manuscript. All authors read and approved the final manuscript.

\section{Funding}

W.J.Y.C. was supported by Graduate Research Fellowship (GRF) from Universiti Putra Malaysia.

Availability of data and materials

Not applicable.

Ethics approval and consent to participate

Not applicable.

\section{Consent for publication}

Not applicable.

\section{Competing interests}

The authors declare that they have no known competing financial interests or personal relationships that could have appeared to influence the work reported in this paper.

Received: 30 June 2020 Accepted: 28 October 2020

Published online: 07 November 2020

\footnotetext{
References

1. Lloyd-Price J, Mahurkar A, Rahnavard G, Crabtree J, Orvis J, Hall AB, et al. Strains, functions and dynamics in the expanded Human Microbiome Project. Nature. 2017;550:61-6.

2. Proctor LM, Creasy HH, Fettweis JM, Lloyd-Price J, Mahurkar A, Zhou W, et al. The integrative Human Microbiome Project. Nature. 2019:569:641-8.
} 
3. Turnbaugh PJ, Ley RE, Hamady M, Fraser-Liggett CM, Knight R, Gordon JI. The Human Microbiome Project. Nature. 2007;449:804-10.

4. Cho I, Blaser MJ. The human microbiome: at the interface of health and disease. Nat Rev Genet. 2012;13:260-70.

5. Smith SB, Ravel J. The vaginal microbiota, host defence and reproductive physiology. J Physiol. 2017;595:451-63.

6. Gajer P, Brotman RM, Bai G, Sakamoto J, Schütte UME, Zhong X, et al. Temporal dynamics of the human vaginal microbiota. Sci Transl Med. 2012:4:132ra52.

7. Fredricks DN. Molecular methods to describe the spectrum and dynamics of the vaginal microbiota. Anaerobe. 2011;17:191-5.

8. Franzosa EA, Hsu T, Sirota-Madi A, Shafquat A, Abu-Ali G, Morgan XC, et al. Sequencing and beyond: integrating molecular 'omics' for microbial community profiling. Nat Rev Microbiol. 2015;13:360-72.

9. Johnson JS, Spakowicz DJ, Hong B-Y, Petersen LM, Demkowicz P, Chen $L$, et al. Evaluation of $16 \mathrm{~S}$ rRNA gene sequencing for species and strainlevel microbiome analysis. Nat Commun. 2019;10:5029.

10. Ravel J, Gajer P, Abdo Z, Schneider GM, Koenig SSK, McCulle SL, et al. Vaginal microbiome of reproductive-age women. Proc Natl Acad Sci USA. 2011;108(Suppl 1):4680-7.

11. Ma B, Forney LJ, Ravel J. Vaginal microbiome: rethinking health and disease. Annu Rev Microbiol. 2012;66:371-89.

12. Hall RA, Noverr MC. Fungal interactions with the human host: exploring the spectrum of symbiosis. Curr Opin Microbiol. 2017:40:58-64.

13. Gow NAR, Hube B. Importance of the Candida albicans cell wall during commensalism and infection. Curr Opin Microbiol. 2012;15:406-12.

14. Zapata HJ, Quagliarello VJ. The microbiota and microbiome in aging: potential implications in health and age-related diseases. J Am Geriatr Soc. 2015;63:776-81.

15. Plummer EL, Vodstrcil LA, Fairley CK, Tabrizi SN, Garland SM, Law MG, et al. Sexual practices have a significant impact on the vaginal microbiota of women who have sex with women. Sci Rep. 2019;9:19749.

16. Mulder M, Radjabzadeh D, Hassing RJ, Heeringa J, Uitterlinden AG, Kraaij $\mathrm{R}$, et al. The effect of antimicrobial drug use on the composition of the genitourinary microbiota in an elderly population. BMC Microbiol. 2019;19:9.

17. Hickey RJ, Zhou X, Settles ML, Erb J, Malone K, Hansmann MA, et al. Vaginal microbiota of adolescent girls prior to the onset of menarche resemble those of reproductive-age women. mBio. 2015;6:e00097-15.

18. Bradford LL, Chibucos MC, Ma B, Bruno V, Ravel J. Vaginal Candida spp. genomes from women with vulvovaginal candidiasis. Pathog Dis. 2017:75:ftx061.

19. Mitra A, MacIntyre DA, Marchesi JR, Lee YS, Bennett PR, Kyrgiou M. The vaginal microbiota, human papillomavirus infection and cervical intraepithelial neoplasia: what do we know and where are we going next? Microbiome. 2016:4:58.

20. van de Wijgert JHHM. The vaginal microbiome and sexually transmitted infections are interlinked: consequences for treatment and prevention. PLoS Med. 2017;14:e1002478.

21. Ziklo N, Vidgen ME, Taing K, Huston WM, Timms P. Dysbiosis of the vaginal microbiota and higher vaginal kynurenine/tryptophan ratio reveals an association with Chlamydia trachomatis genital infections. Front Cell Infect Microbiol. 2018:8:1.

22. Shannon B, Gajer P, Yi TJ, Ma B, Humphrys MS, Thomas-Pavanel J, et al. Distinct effects of the cervicovaginal microbiota and herpes simplex type 2 infection on female genital tract immunology. J Infect Dis. 2017:215:1366-75

23. Eastment MC, McClelland RS. Vaginal microbiota and susceptibility to HIV. AIDS. 2018;32:687-98.

24. Ceccarani C, Foschi C, Parolin C, D'Antuono A, Gaspari V, Consolandi C, et al. Diversity of vaginal microbiome and metabolome during genital infections. Sci Rep. 2019;9::14095.

25. Amabebe E, Anumba DOC. The vaginal microenvironment: the physiologic role of lactobacilli. Front Med (Lausanne). 2018;5:181.

26. O'Toole PW, Marchesi JR, Hill C. Next-generation probiotics: the spectrum from probiotics to live biotherapeutics. Nat Microbiol. 2017;2:17057.

27. van Nood E, Vrieze A, Nieuwdorp M, Fuentes S, Zoetendal EG, de Vos WM, et al. Duodenal infusion of donor feces for recurrent Clostridium difficile. N Engl J Med. 2013;368:407-15.
28. Lev-Sagie A, Goldman-Wohl D, Cohen Y, Dori-Bachash M, Leshem A, Mor U, et al. Vaginal microbiome transplantation in women with intractable bacterial vaginosis. Nat Med. 2019;25:1500-4.

29. Larsson P-G, Brandsborg E, Forsum U, Pendharkar S, Andersen KK, Nasic $\mathrm{S}$, et al. Extended antimicrobial treatment of bacterial vaginosis combined with human lactobacilli to find the best treatment and minimize the risk of relapses. BMC Infect Dis. 2011;11:223.

30. Anukam K, Osazuwa E, Ahonkhai I, Ngwu M, Osemene G, Bruce AW, et al. Augmentation of antimicrobial metronidazole therapy of bacterial vaginosis with oral probiotic Lactobacillus rhamnosus GR-1 and Lactobacillus reuteri RC-14: randomized, double-blind, placebo controlled trial. Microbes Infect. 2006:8:1450-4.

31. Castro-Bravo N, Wells JM, Margolles A, Ruas-Madiedo P. Interactions of surface exopolysaccharides from Bifidobacterium and Lactobacillus within the intestinal environment. Front Microbiol. 2018;9:2426.

32. Kleerebezem M, Hols P, Bernard E, Rolain T, Zhou M, Siezen RJ, et al. The extracellular biology of the lactobacilli. FEMS Microbiol Rev. 2010:34:199-230

33. Liu Z, Zhang Z, Qiu L, Zhang F, Xu X, Wei H, et al. Characterization and bioactivities of the exopolysaccharide from a probiotic strain of Lactobacillus plantarum WLPL04. J Dairy Sci. 2017;100:6895-905.

34. Allonsius CN, Vandenheuvel D, Oerlemans EFM, Petrova MI, Donders GGG, Cos P, et al. Inhibition of Candida albicans morphogenesis by chitinase from Lactobacillus rhamnosus GG. Sci Rep. 2019:9:2900.

35. Ahn KB, Baik JE, Park O-J, Yun C-H, Han SH. Lactobacillus plantarum lipoteichoic acid inhibits biofilm formation of Streptococcus mutans. PLOS ONE. 2018:13:e0192694.

36. Brooks JP, Buck GA, Chen G, Diao L, Edwards DJ, Fettweis JM, et al. Changes in vaginal community state types reflect major shifts in the microbiome. Microb Ecol Health Dis. 2017;28:1303265.

37. Zheng N, Guo R, Yao Y, Jin M, Cheng Y, Ling Z. Lactobacillus iners is associated with vaginal dysbiosis in healthy pregnant women: a preliminary study. Biomed Res Int. 2019;2019:6079734.

38. Li F, Brix S, Wang Z, Chen C, Song L, Hao L, et al. The metagenome of the female upper reproductive tract. Gigascience. 2018;7:giy107.

39. Drell T, Lillsaar T, Tummeleht L, Simm J, Aaspöllu A, Väin E, et al. Characterization of the vaginal micro- and mycobiome in asymptomatic reproductive-age Estonian women. PLoS ONE. 2013;8:e54379.

40. Kroon SJ, Ravel J, Huston WM. Cervicovaginal microbiota, women's health, and reproductive outcomes. Fertil Steril. 2018:110:327-36.

41. Younes JA, Lievens E, Hummelen R, van der Westen R, Reid G, Petrova MI. Women and their microbes: the unexpected friendship. Trends Microbiol. 2018;26:16-32.

42. Hickey RJ, Zhou X, Pierson JD, Ravel J, Forney LJ. Understanding vaginal microbiome complexity from an ecological perspective. Transl Res. 2012;160:267-82.

43. Sabo MC, Balkus JE, Richardson BA, Srinivasan S, Kimani J, Anzala O, et al. Association between vaginal washing and vaginal bacterial concentrations. PLOS ONE. 2019:14:e210825.

44. Huang B, Fettweis JM, Brooks JP, Jefferson KK, Buck GA. The changing landscape of the vaginal microbiome. Clin Lab Med. 2014;34:747-61.

45. Doyle R, Gondwe A, Fan Y-M, Maleta K, Ashorn P, Klein N, et al. A Lactobacillus-deficient vaginal microbiota dominates postpartum women in rural Malawi. Appl Environ Microbiol. 2018;84:e02150-17.

46. van de Wijgert JHHM, Borgdorff H, Verhelst $\mathrm{R}$, Crucitti T, Francis $\mathrm{S}$, Verstraelen $\mathrm{H}$, et al. The vaginal microbiota: what have we learned after a decade of molecular characterization? PLOS ONE. 2014;9:e105998.

47. DiGiulio DB, Callahan BJ, McMurdie PJ, Costello EK, Lyell DJ, Robaczewska A, et al. Temporal and spatial variation of the human microbiota during pregnancy. Proc Natl Acad Sci USA. 2015;112:11060-5.

48. De Seta F, Campisciano G, Zanotta N, Ricci G, Comar M. The vaginal community state types microbiome-immune network as key factor for bacterial vaginosis and aerobic vaginitis. Front Microbiol. 2019;10:2451.

49. Jakobsson T, Forsum U. Lactobacillus iners: a marker of changes in the vaginal flora? J Clin Microbiol. 2007:45:3145.

50. Verstraelen H, Verhelst R, Claeys G, De Backer E, Temmerman M, Vaneechoutte M. Longitudinal analysis of the vaginal microflora in pregnancy suggests that $L$. crispatus promotes the stability of the normal vaginal microflora and that L. gasseri and/or L. iners are more conducive to the occurrence of abnormal vaginal microflora. BMC Microbiol. 2009:9:116. 
51. Breshears LM, Edwards VL, Ravel J, Peterson ML. Lactobacillus crispatus inhibits growth of Gardnerella vaginalis and Neisseria gonorrhoeae on a porcine vaginal mucosa model. BMC Microbiol. 2015;15:276.

52. Fuochi V, Cardile V, Petronio Petronio G, Furneri PM. Biological properties and production of bacteriocins-like-inhibitory substances by Lactobacillus sp. strains from human vagina. J Appl Microbiol. 2019;126:1541-50.

53. France MT, Mendes-Soares H, Forney LJ. Genomic comparisons of Lactobacillus crispatus and Lactobacillus iners reveal potential ecological drivers of community composition in the vagina. Appl Environ Microbiol. 2016;82:7063-73.

54. Edwards VL, Smith SB, McComb EJ, Tamarelle J, Ma B, Humphrys MS, et al. The cervicovaginal microbiota-host interaction modulates Chlamydia trachomatis infection. mBio. 2019;10:e01548-19.

55. Witkin SS, Mendes-Soares H, Linhares IM, Jayaram A, Ledger WJ, Forney LJ. Influence of vaginal bacteria and D- and L-lactic acid isomers on vaginal extracellular matrix metalloproteinase inducer: implications for protection against upper genital tract infections. mBio. 2013;4:e00460-13.

56. Borgdorff $\mathrm{H}$, van der Veer $\mathrm{C}$, van Houdt $\mathrm{R}$, Alberts $\mathrm{CJ}$, de Vries $\mathrm{HJ}$, Bruisten SM, et al. The association between ethnicity and vaginal microbiota composition in Amsterdam, the Netherlands. PLOS ONE. 2017;12:e0181135.

57. van de Wijgert JHHM, Verwijs MC, Gill AC, Borgdorff $H$, van der Veer $C$, Mayaud P. Pathobionts in the vaginal microbiota: individual participant data meta-analysis of three sequencing studies. Front Cell Infect Microbiol. 2020;10:129.

58. Kwak W, Han Y-H, Seol D, Kim H, Ahn H, Jeong M, et al. Complete genome of Lactobacillus iners $\mathrm{KY}$ using Flongle provides insight into the genetic background of optimal adaption to vaginal econiche. Front Microbiol. 2020;11:1048.

59. Chao X-P, Sun T-T, Wang S, Fan Q-B, Shi H-H, Zhu L, et al. Correlation between the diversity of vaginal microbiota and the risk of high-risk human papillomavirus infection. Int J Gynecol Cancer. 2019;29:28-34.

60. Kyrgiou M, Mitra A, Moscicki A-B. Does the vaginal microbiota play a role in the development of cervical cancer? Transl Res. 2017;179:168-82.

61. Lee JE, Lee S, Lee H, Song Y-M, Lee K, Han MJ, et al. Association of the vaginal microbiota with human papillomavirus infection in a Korean twin cohort. PLOS ONE. 2013;8:e63514.

62. Kwasniewski W, Wolun-Cholewa M, Kotarski J, Warchol W, Kuzma D, Kwasniewska A, et al. Microbiota dysbiosis is associated with HPVinduced cervical carcinogenesis. Oncol Lett. 2018;16:7035-47.

63. Zhou Y, Wang L, Pei F, Ji M, Zhang F, Sun Y, et al. Patients with LR-HPV infection have a distinct vaginal microbiota in comparison with healthy controls. Front Cell Infect Microbiol. 2019;9:294.

64. Brusselaers N, Shrestha S, van de Wijgert J, Verstraelen H. Vaginal dysbiosis and the risk of human papillomavirus and cervical cancer: systematic review and meta-analysis. Am J Obstet Gynecol. 2019;221:9-18. e18.

65. Mathema B, Cross E, Dun E, Park S, Bedell J, Slade B, et al. Prevalence of vaginal colonization by drug-resistant Candida species in college-age women with previous exposure to over-the-counter azole antifungals. Clin Infect Dis. 2001;33:e23-7.

66. Farr A, Kiss H, Holzer I, Husslein P, Hagmann M, Petricevic L. Effect of asymptomatic vaginal colonization with Candida albicans on pregnancy outcome. Acta Obstet Gynecol Scand. 2015;94:989-96.

67. Ward TL, Dominguez-Bello MG, Heisel T, Al-Ghalith G, Knights D, Gale CA. Development of the human mycobiome over the first month of life and across body sites. mSystems. 2018;3:e00140-17.

68. Bliss JM, Basavegowda KP, Watson WJ, Sheikh AU, Ryan RM. Vertical and horizontal transmission of Candida albicans in very low birth weight infants using DNA fingerprinting techniques. Pediatr Infect Dis J. 2008:27:231-5.

69. Brown SE, Schwartz JA, Robinson CK, O'Hanlon DE, Bradford LL, He X, et al. The vaginal microbiota and behavioral factors associated with genital Candida albicans detection in reproductive-age women. Sex Transm Dis. 2019;46:753-8.

70. Guzel AB, Ilkit M, Akar T, Burgut R, Demir SC. Evaluation of risk factors in patients with vulvovaginal candidiasis and the value of chromID Candida agar versus CHROMagar Candida for recovery and presumptive identification of vaginal yeast species. Med Mycol. 2011;49:16-25.
71. Gonçalves B, Ferreira C, Alves CT, Henriques M, Azeredo J, Silva S. Vulvovaginal candidiasis: epidemiology, microbiology and risk factors. Crit Rev Microbiol. 2016;42:905-27.

72. Sobel JD. Vulvovaginal candidosis. Lancet. 2007;369:1961-71.

73. Fidel PL, Vazquez JA, Sobel JD. Candida glabrata: review of epidemiology, pathogenesis, and clinical disease with comparison to C. albicans. Clin Microbiol Rev. 1999;12:80-96.

74. Denning DW, Kneale M, Sobel JD, Rautemaa-Richardson R. Global burden of recurrent vulvovaginal candidiasis: a systematic review. Lancet Infect Dis. 2018;18:e339-47.

75. Förster TM, Mogavero S, Dräger A, Graf K, Polke M, Jacobsen ID, et al. Enemies and brothers in arms: Candida albicans and gram-positive bacteria. Cell Microbiol. 2016;18:1709-15.

76. Sadeghi G, Ebrahimi-Rad M, Mousavi SF, Shams-Ghahfarokhi M, Razzaghi-Abyaneh M. Emergence of non-Candida albicans species: epidemiology, phylogeny and fluconazole susceptibility profile. J Mycol Med. 2018;28:51-8.

77. Ng KP, Kuan CS, Kaur H, Na SL, Atiya N, Velayuthan RD. Candida species epidemiology 2000-2013: a laboratory-based report. Trop Med Int Health. 2015;20:1447-53.

78. Bitew A, Abebaw Y. Vulvovaginal candidiasis: species distribution of Candida and their antifungal susceptibility pattern. BMC Womens Health. 2018;18:94.

79. De Vos MM, Cuenca-Estrella M, Boekhout T, Theelen B, Matthijs N, Bauters T, et al. Vulvovaginal candidiasis in a Flemish patient population. Clin Microbiol Infect. 2005;11:1005-11.

80. Rodríguez-Cerdeira C, Gregorio MC, Molares-Vila A, López-Barcenas A, Fabbrocini G, Bardhi B, et al. Biofilms and vulvovaginal candidiasis. Colloids Surf B Biointerfaces. 2019;174:110-25.

81. Aballéa S, Guelfucci F, Wagner J, Khemiri A, Dietz J-P, Sobel J, et al. Subjective health status and health-related quality of life among women with recurrent vulvovaginal candidosis (RVVC) in Europe and the USA. Health Qual Life Outcomes. 2013;11:169.

82. Nobile CJ, Johnson AD. Candida albicans biofilms and human disease. Annu Rev Microbiol. 2015;69:71-92.

83. Berman J. Candida albicans. Curr Biol. 2012;22:R620-2.

84. Bradford LL, Ravel J. The vaginal mycobiome: a contemporary perspective on fungi in women's health and diseases. Virulence. 2017;8:342-51.

85. Swidsinski A, Guschin A, Tang Q, Dörffel Y, Verstraelen H, Tertychnyy A, et al. Vulvovaginal candidiasis: histologic lesions are primarily polymicrobial and invasive and do not contain biofilms. Am J Obstet Gynecol. 2019;220::91.e91-8.

86. Roselletti E, Monari C, Sabbatini S, Perito S, Vecchiarelli A, Sobel JD, et al. A role for yeast/pseudohyphal cells of Candida albicans in the correlated expression of NLRP3 inflammasome inducers in women with acute vulvovaginal candidiasis. Front Microbiol. 2019;10:2669.

87. Krüger W, Vielreicher S, Kapitan M, Jacobsen ID, Niemiec MJ. Fungalbacterial interactions in health and disease. Pathogens. 2019;8:70.

88. Guo R, Zheng N, Lu H, Yin H, Yao J, Chen Y. Increased diversity of fungal flora in the vagina of patients with recurrent vaginal candidiasis and allergic rhinitis. Microb Ecol. 2012;64:918-27.

89. Zheng N-N, Guo X-C, Lv W, Chen X-X, Feng G-F. Characterization of the vaginal fungal flora in pregnant diabetic women by $18 \mathrm{~S}$ rRNA sequencing. Eur J Clin Microbiol Infect Dis. 2013;32:1031-40.

90. Bradshaw CS, Brotman RM. Making inroads into improving treatment of bacterial vaginosis - striving for long-term cure. BMC Infect Dis. 2015;15:292.

91. Peebles K, Velloza J, Balkus JE, McClelland RS, Barnabas RV. High global burden and costs of bacterial vaginosis: a systematic review and metaAnalysis. Sex Transm Dis. 2019;46:304-11.

92. Coleman JS, Gaydos CA. Molecular diagnosis of bacterial vaginosis: an update. J Clin Microbiol. 2018;56:e00342-18.

93. Muzny CA, Laniewski P, Schwebke JR, Herbst-Kralovetz MM. Host-vaginal microbiota interactions in the pathogenesis of bacterial vaginosis. Curr Opin Infect Dis. 2020;33:59-65.

94. Ravel J, Brotman RM, Gajer P, Ma B, Nandy M, Fadrosh DW, et al. Daily temporal dynamics of vaginal microbiota before, during and after episodes of bacterial vaginosis. Microbiome. 2013;1::29.

95. Shimaoka M, Yo Y, Doh K, Kotani Y, Suzuki A, Tsuji I, et al. Association between preterm delivery and bacterial vaginosis with or without treatment. Sci Rep. 2019;9:509. 
96. Gondwe T, Ness R, Totten PA, Astete S, Tang G, Gold MA, et al. Novel bacterial vaginosis-associated organisms mediate the relationship between vaginal douching and pelvic inflammatory disease. Sex Transm Infect. 2020;96:439-44.

97. Bayigga L, Kateete DP, Anderson DJ, Sekikubo M, Nakanjako D. Diversity of vaginal microbiota in sub-Saharan Africa and its effects on HIV transmission and prevention. Am J Obstet Gynecol. 2019;220:155-66.

98. Bilardi JE, Walker S, Temple-Smith M, McNair R, Mooney-Somers J, Bellhouse C, et al. The burden of bacterial vaginosis: women's experience of the physical, emotional, sexual and social impact of living with recurrent bacterial vaginosis. PLoS One. 2013;8:e74378.

99. Soper DE. Bacterial vaginosis and surgical site infections. Am J Obstet Gynecol. 2019;222:219-23.

100. Muzny CA, Taylor CM, Swords WE, Tamhane A, Chattopadhyay D, Cerca $\mathrm{N}$, et al. An updated conceptual model on the pathogenesis of bacterial vaginosis. J Infect Dis. 2019;220:1399-405.

101. Muzny CA, Blanchard E, Taylor CM, Aaron KJ, Talluri R, Griswold ME, et al. Identification of key bacteria involved in the induction of incident bacterial vaginosis: a prospective study. J Infect Dis. 2018;218:966-78.

102. Gilbert NM, Lewis WG, Li G, Sojka DK, Lubin JB, Lewis AL. Gardnerella vaginalis and Prevotella bivia trigger distinct and overlapping phenotypes in a mouse model of bacterial vaginosis. J Infect Dis. 2019;220:1099-108

103. Castro J, Machado D, Cerca N. Unveiling the role of Gardnerella vaginalis in polymicrobial bacterial vaginosis biofilms: the impact of other vaginal pathogens living as neighbors. ISME J. 2019;13:1306-17.

104. Swidsinski A, Mendling W, Loening-Baucke V, Swidsinski S, Dörffel Y, Scholze J, et al. An adherent Gardnerella vaginalis biofilm persists on the vaginal epithelium after standard therapy with oral metronidazole. Am J Obstet Gynecol. 2008;198::97.e91-6.

105. Machado A, Cerca N. Influence of biofilm formation by Gardnerella vaginalis and other anaerobes on bacterial vaginosis. J Infect Dis. 2015;212:1856-61.

106. Gosmann C, Anahtar MN, Handley SA, Farcasanu M, Abu-Ali G, Bowman $B A$, et al. Lactobacillus-deficient cervicovaginal bacterial communities are associated with increased HIV acquisition in young South African women. Immunity. 2017:46:29-37.

107. Peipert JF, Lapane KL, Allsworth JE, Redding CA, Blume JD, Stein MD. Bacterial vaginosis, race, and sexually transmitted infections: does race modify the association? Sex Transm Dis. 2008;35:363-7.

108. McClelland RS, Lingappa JR, Srinivasan S, Kinuthia J, John-Stewart GC, Jaoko W, et al. Evaluation of the association between the concentrations of key vaginal bacteria and the increased risk of HIV acquisition in African women from five cohorts: a nested case-control study. Lancet Infect Dis. 2018;18:554-64.

109. Cone RA. Vaginal microbiota and sexually transmitted infections that may influence transmission of cell-associated HIV. J Infect Dis. 2014;210::616-21.

110. Nardini P, Ñahui Palomino RA, Parolin C, Laghi L, Foschi C, Cevenini $R$, et al. Lactobacillus crispatus inhibits the infectivity of Chlamydia trachomatis elementary bodies, in vitro study. Sci Rep. 2016;6:29024.

111. Gong Z, Luna Y, Yu P, Fan H. Lactobacilli inactivate Chlamydia trachomatis through lactic acid but not $\mathrm{H}_{2} \mathrm{O}_{2}$. PLOS ONE. 2014:9:e107758.

112. Rowley J, Vander Hoorn S, Korenromp E, Low N, Unemo M, Abu-Raddad LJ, et al. Chlamydia, gonorrhoea, trichomoniasis and syphilis: global prevalence and incidence estimates, 2016. Bull World Health Organ. 2019;97:548-62P.

113. Harp DF, Chowdhury I. Trichomoniasis: evaluation to execution. Eur J Obstet Gynecol Reprod Biol. 2011;157:3-9.

114. McCormack D, Koons K. Sexually transmitted infections. Emerg Med Clin N Am. 2019;37:725-38.

115. Eisinger RW, Erbelding E, Fauci AS. Refocusing research on sexually transmitted infections. J Infect Dis. 2020;222:1432-4.

116. Zhu H, Shen Z, Luo H, Zhang W, Zhu X. Chlamydia trachomatis infection-associated risk of cervical cancer: a meta-analysis. Med (Baltim). 2016;95:e3077.

117. Johnson HL, Ghanem KG, Zenilman JM, Erbelding EJ. Sexually transmitted infections and adverse pregnancy outcomes among women attending inner city public sexually transmitted diseases clinics. Sex Transm Dis. 2011;38:167-71.
118. van de Wijgert JHHM, Morrison CS, Brown J, Kwok C, Van Der Pol B, Chipato T, et al. Disentangling contributions of reproductive tract infections to HIV acquisition in African women. Sex Transm Dis. 2009;36:357-64.

119. Masson L, Barnabas S, Deese J, Lennard K, Dabee S, Gamieldien H, et al. Inflammatory cytokine biomarkers of asymptomatic sexually transmitted infections and vaginal dysbiosis: a multicentre validation study. Sex Transm Infect. 2019;95:5-12.

120. Brotman RM, Bradford LL, Conrad M, Gajer P, Ault K, Peralta L, et al. Association between Trichomonas vaginalis and vaginal bacterial community composition among reproductive-age women. Sex Transm Dis. 2012;39:807-12.

121. Galvin SR, Cohen MS. The role of sexually transmitted diseases in HIV transmission. Nat Rev Microbiol. 2004;2:33-42.

122. Lewis J, Price MJ, Horner PJ, White PJ. Genital Chlamydia trachomatis infections clear more slowly in men than women, but are less likely to become established. J Infect Dis. 2017;216:237-44.

123. Stapleton AE. The vaginal microbiota and urinary tract infection. Microbiol Spectrom. 2016. https://doi.org/10.1128/microbiolspec. UTI-0025-2016.

124. Qiao L-D, Chen S, Yang Y, Zhang K, Zheng B, Guo H-F, et al. Characteristics of urinary tract infection pathogens and their in vitro susceptibility to antimicrobial agents in China: data from a multicenter study. BM. Open. 2013;3:e004152.

125. Flores-Mireles AL, Walker JN, Caparon M, Hultgren SJ. Urinary tract infections: epidemiology, mechanisms of infection and treatment options. Nat Rev Microbiol. 2015;13:269-84.

126. Kline KA, Lewis AL. Gram-positive uropathogens, polymicrobial urinary tract infection, and the emerging microbiota of the urinary tract. Microbiol Spectr. 2016. https://doi.org/10.1128/microbiolspec.UTI-0012-2012.

127. Kwon YE, Oh D-J, Kim MJ, Choi HM. Prevalence and clinical characteristics of asymptomatic pyuria in chronic kidney disease. Ann Lab Med. 2020;40:238-44.

128. Chu CM, Lowder JL. Diagnosis and treatment of urinary tract infections across age groups. Am J Obstet Gynecol. 2018;219:40-51.

129. Thomas-White K, Forster SC, Kumar N, Van Kuiken M, Putonti C, Stares MD, et al. Culturing of female bladder bacteria reveals an interconnected urogenital microbiota. Nat Commun. 2018;9:1557.

130. Terlizzi ME, Gribaudo G, Maffei ME. UroPathogenic Escherichia coli (UPEC) infections: virulence factors, bladder responses, antibiotic, and non-antibiotic antimicrobial strategies. Front Microbiol. 2017;8:1566.

131. Komesu YM, Dinwiddie DL, Richter HE, Lukacz ES, Sung VW, Siddiqui NY, et al. Defining the relationship between vaginal and urinary microbiomes. Am J Obstet Gynecol. 2020;222:151.e1-10.

132. Kirjavainen PV, Pautler S, Baroja ML, Anukam K, Crowley K, Carter K, et al. Abnormal immunological profile and vaginal microbiota in women prone to urinary tract infections. Clin Vaccine Immunol. 2009;16:29-36.

133. Gilbert NM, O'Brien VP, Lewis AL. Transient microbiota exposures activate dormant Escherichia coli infection in the bladder and drive severe outcomes of recurrent disease. PLoS Pathog. 2017;13:e1006238.

134. Pierson JD, Hansmann MA, Davis CC, Forney LJ. The effect of vaginal microbial communities on colonization by Staphylococcus aureus with the gene for toxic shock syndrome toxin 1 (TSST-1): a case-control study. Pathog Dis. 2018;76:fty015.

135. Schlievert PM, Nemeth KA, Davis CC, Peterson ML, Jones BE. Staphylococcus aureus exotoxins are present in vivo in tampons. Clin Vaccine Immunol. 2010;17:722-7.

136. Schlievert PM. Effect of non-absorbent intravaginal menstrual/contraceptive products on Staphylococcus aureus and production of the superantigen TSST-1. Eur J Clin Microbiol Infect Dis. 2020;39:31-8.

137. Nonfoux L, Chiaruzzi M, Badiou C, Baude J, Tristan A, Thioulouse J, et al. Impact of currently marketed tampons and menstrual cups on Staphylococcus aureus growth and toxic shock syndrome toxin 1 production in vitro. Appl Environ Microbiol. 2018;84:e00351-18.

138. Carter K, Bassis C, McKee K, Bullock K, Eastman A, Young V, et al. The impact of tampon use on the vaginal microbiota across four menstrual cycles. Am J Obstet Gynecol. 2018;219:639.

139. MacPhee RA, Miller WL, Gloor GB, McCormick JK, Hammond J-A, Burton $\mathrm{JP}$, et al. Influence of the vaginal microbiota on toxic shock syndrome toxin 1 production by Staphylococcus aureus. Appl Environ Microbiol. 2013;79:1835-42. 
140. Leroy F, De Vuyst L. Lactic acid bacteria as functional starter cultures for the food fermentation industry. Trends Food Sci Technol. 2004; 15:67-78

141. George F, Daniel C, Thomas M, Singer E, Guilbaud A, Tessier FJ, et al. Occurrence and dynamism of lactic acid bacteria in distinct ecological niches: a multifaceted functional health perspective. Front Microbiol. 2018;9:2899.

142. Kerry RG, Patra JK, Gouda S, Park Y, Shin H-S, Das G. Benefaction of probiotics for human health: a review. J Food Drug Anal. 2018;26:927-39.

143. Ghosh T, Beniwal A, Semwal A, Navani NK. Mechanistic insights into probiotic properties of lactic acid bacteria associated with ethnic fermented dairy products. Front Microbiol. 2019;10:502.

144. Mattia A, Merker R. Regulation of probiotic substances as ingredients in foods: premarket approval or "Generally Recognized as Safe" notification. Clin Infect Dis. 2008;46::115-8.

145. Venegas-Ortega MG, Flores-Gallegos AC, Martínez-Hernández JL, Aguilar CN, Nevárez-Moorillón GV. Production of bioactive peptides from lactic acid bacteria: a sustainable approach for healthier foods. Compr Rev Food Sci Food Saf. 2019;18:1039-51.

146. Iyer R, Tomar SK, Uma Maheswari T, Singh R. Streptococcus thermophilus strains: multifunctional lactic acid bacteria. Int Dairy J. 2010;20:133-41.

147. Cui Y, Xu T, Qu X, Hu T, Jiang X, Zhao C. New insights into various production characteristics of Streptococcus thermophilus strains. Int J Mol Sci. 2016;17:1701.

148. Reid G, Younes JA, Van der Mei HC, Gloor GB, Knight R, Busscher HJ. Microbiota restoration: natural and supplemented recovery of human microbial communities. Nat Rev Microbiol. 2010;9:27.

149. Prabhurajeshwar C, Chandrakanth RK. Probiotic potential of lactobacilli with antagonistic activity against pathogenic strains: an in vitro validation for the production of inhibitory substances. Biomed J. 2017:40:270-83.

150. Chew SY, Cheah YK, Seow HF, Sandai D, Than LTL. Probiotic Lactobacillus rhamnosus GR-1 and Lactobacillus reuteri RC-14 exhibit strong antifungal effects against vulvovaginal candidiasis-causing Candida glabrata isolates. J Appl Microbiol. 2015;118:1180-90.

151. Singh TP, Kaur G, Kapila S, Malik RK. Antagonistic activity of Lactobacillus reuteri strains on the adhesion characteristics of selected pathogens. Front Microbiol. 2017:8:486.

152. Humphreys GJ, McBain AJ. Antagonistic effects of Streptococcus and Lactobacillus probiotics in pharyngeal biofilms. Lett Appl Microbiol. 2019;68:303-12.

153. Gaspar C, Donders GG, Palmeira-de-Oliveira R, Queiroz JA, Tomaz C, Martinez-de-Oliveira J, et al. Bacteriocin production of the probiotic Lactobacillus acidophilus KS400. AMB Express. 2018;8:153.

154. Turovskiy Y, Ludescher RD, Aroutcheva AA, Faro S, Chikindas ML. Lactocin 160, a bacteriocin produced by vaginal Lactobacillus rhamnosus, targets cytoplasmic membranes of the vaginal pathogen, Gardnerella vaginalis. Probiotics Antimicrob Proteins. 2009;1:67-74.

155. Donders GGG, Ruban K, Bellen G. Selecting anti-microbial treatment of aerobic vaginitis. Curr Infect Dis Rep. 2015;17:477.

156. Donders GGG, Bellen G, Grinceviciene S, Ruban K, Vieira-Baptista P. Aerobic vaginitis: no longer a stranger. Res Microbiol. 2017;168:845-58.

157. Beigi RH, Austin MN, Meyn LA, Krohn MA, Hillier SL. Antimicrobial resistance associated with the treatment of bacterial vaginosis. Am J Obstet Gynecol. 2004;191:1124-9.

158. Austin MN, Beigi RH, Meyn LA, Hillier SL. Microbiologic response to treatment of bacterial vaginosis with topical clindamycin or metronidazole. J Clin Microbiol. 2005:43:4492-7.

159. Bertuccini L, Russo R, losi F, Superti F. Effects of Lactobacillus rhamnosus and Lactobacillus acidophilus on bacterial vaginal pathogens. Int J Immunopathol Pharmacol. 2017;30:163-7.

160. De Alberti D, Russo R, Terruzzi F, Nobile V, Ouwehand AC. Lactobacilli vaginal colonisation after oral consumption of Respecta ${ }^{\circledR}$ complex: a randomised controlled pilot study. Arch Gynecol Obstet. 2015;292:861-7

161. Mezzasalma V, Manfrini E, Ferri E, Boccarusso M, Di Gennaro P, Schiano I, et al. Orally administered multispecies probiotic formulations to prevent uro-genital infections: a randomized placebo-controlled pilot study. Arch Gynecol Obstet. 2017;295:163-72.

162. Wang S, Wang Q, Yang E, Yan L, Li T, Zhuang H. Antimicrobial compounds produced by vaginal Lactobacillus crispatus are able to strongly inhibit Candida albicans growth, hyphal formation and regulate virulence-related gene expressions. Front Microbiol. 2017;8:564.

163. Li T, Liu Z, Zhang X, Chen X, Wang S. Local probiotic Lactobacillus crispatus and Lactobacillus delbrueckii exhibit strong antifungal effects against vulvovaginal candidiasis in a rat model. Front Microbiol. 2019;10:1033.

164. Heczko PB, Tomusiak A, Adamski P, Jakimiuk AJ, Stefański G, Mikołajczyk-Cichońska A, et al. Supplementation of standard antibiotic therapy with oral probiotics for bacterial vaginosis and aerobic vaginitis: a randomised, double-blind, placebo-controlled trial. BMC Womens Health. 2015;15:115.

165. Balzaretti S, Taverniti V, Rondini G, Marcolegio G, Minuzzo M, Remagni MC, et al. The vaginal isolate Lactobacillus paracasei LPC-S01 (DSM 26760) is suitable for oral administration. Front Microbiol. 2015;6:952.

166. Reid G, Bruce AW, Fraser N, Heinemann C, Owen J, Henning B. Oral probiotics can resolve urogenital infections. FEMS Immunol Med Microbiol. 2001;30:49-52.

167. Buggio L, Somigliana E, Borghi A, Vercellini P. Probiotics and vaginal microecology: fact or fancy? BMC Womens Health. 2019;19:25.

168. Bohbot JM, Daraï E, Bretelle F, Brami G, Daniel C, Cardot JM. Efficacy and safety of vaginally administered lyophilized Lactobacillus crispatus IP 174178 in the prevention of bacterial vaginosis recurrence. J Gynecol Obstet Hum Reprod. 2018;47:81-6.

169. Vicariotto F, Mogna L, Del Piano M. Effectiveness of the two microorganisms Lactobacillus fermentum LF15 and Lactobacillus plantarum LP01, formulated in slow-release vaginal tablets, in women affected by bacterial vaginosis: a pilot study. J Clin Gastroenterol. 2014;48:106-12.

170. Palma E, Recine N, Domenici L, Giorgini M, Pierangeli A, Panici PB. Longterm Lactobacillus rhamnosus BMX 54 application to restore a balanced vaginal ecosystem: a promising solution against HPV-infection. BMC Infect Dis. 2018;18:13.

171. Recine N, Palma E, Domenici L, Giorgini M, Imperiale L, Sassu C, et al. Restoring vaginal microbiota: biological control of bacterial vaginosis. A prospective case-control study using Lactobacillus rhamnosus BMX 54 as adjuvant treatment against bacterial vaginosis. Arch Gynecol Obstet. 2016;293:101-7.

172. van de Wijgert JHHM, Verwijs MC, Agaba SK, Bronowski C, Mwambarangwe $L$, Uwineza $M$, et al. Intermittent lactobacilli-containing vaginal probiotic or metronidazole use to prevent bacterial vaginosis recurrence: a pilot study incorporating microscopy and sequencing. Sci Rep. 2020;10:3884

173. Russo R, Superti F, Karadja E, De Seta F. Randomised clinical trial in women with recurrent vulvovaginal candidiasis: efficacy of probiotics and lactoferrin as maintenance treatment. Mycoses. 2019;62:328-35.

174. Xie HY, Feng D, Wei DM, Mei L, Chen H, Wang X, et al. Probiotics for vulvovaginal candidiasis in non-pregnant women. Cochrane Database Syst Rev. 2017;11:CD010496.

175. Chehoud C, Stieh DJ, Bailey AG, Laughlin AL, Allen SA, McCotter KL, et al. Associations of the vaginal microbiota with HIV infection, bacterial vaginosis, and demographic factors. AIDS. 2017;31:895-904.

176. Spear GT, St John E, Zariffard M. Bacterial vaginosis and human immunodeficiency virus infection. AIDS Res Ther. 2007:4:25.

177. Brichacek B, Lagenaur LA, Lee PP, Venzon D, Hamer DH. In vivo evaluation of safety and toxicity of a Lactobacillus jensenii producing modified cyanovirin- $\mathrm{N}$ in a rhesus macaque vaginal challenge model. PLoS ONE. 2013:8:e78817.

178. Palomino RAN, Zicari S, Vanpouille C, Vitali B, Margolis L. Vaginal Lactobacillus inhibits HIV-1 replication in human tissues ex vivo. Front Microbiol. 2017:8:906

179. Martín V, Maldonado A, Fernández L, Rodríguez JM, Connor RI. Inhibition of human immunodeficiency virus type 1 by lactic acid bacteria from human breastmilk. Breastfeed Med. 2010;5:153-8.

180. Su Y, Zhang B, Su L. CD4 detected from Lactobacillus helps understand the interaction between Lactobacillus and HIV. Microbiol Res. 2013;168:273-7.

181. Palomino RAÑ, Vanpouille C, Laghi L, Parolin C, Melikov K, Backlund P, et al. Extracellular vesicles from symbiotic vaginal lactobacilli inhibit HIV-1 infection of human tissues. Nat Commun. 2019;10:5656.

182. Spurbeck RR, Arvidson CG. Lactobacilli at the front line of defense against vaginally acquired infections. Future Microbiol. 2011;6:567-82. 
183. Sanders ME, Merenstein DJ, Reid G, Gibson GR, Rastall RA. Probiotics and prebiotics in intestinal health and disease: from biology to the clinic. Nat Rev Gastroenterol Hepatol. 2019;16:605-16.

184. Lebeer S, Vanderleyden J, De Keersmaecker SCJ. Genes and molecules of lactobacilli supporting probiotic action. Microbiol Mol Biol Rev. 2008;72:728-64.

185. Lebeer S, Vanderleyden J, De Keersmaecker SC. Host interactions of probiotic bacterial surface molecules: comparison with commensals and pathogens. Nat Rev Microbiol. 2010;8:171-84.

186. Hajfarajollah H, Eslami P, Mokhtarani B, Akbari Noghabi K. Biosurfactants from probiotic bacteria: a review. Biotechnol Appl Biochem. 2018:65:768-83.

187. Sanders ME, Benson A, Lebeer S, Merenstein DJ, Klaenhammer TR. Shared mechanisms among probiotic taxa: implications for general probiotic claims. Curr Opin Biotechnol. 2018;49:207-16.

188. Duchêne M-C, Rolain T, Knoops A, Courtin P, Chapot-Chartier M-P, Dufrêne YF, et al. Distinct and specific role of NIpC/P60 endopeptidases LytA and LytB in cell elongation and division of Lactobacillus plantarum. Front Microbiol. 2019;10:713.

189. Delcour J, Ferain T, Deghorain M, Palumbo E, Hols P. The biosynthesis and functionality of the cell-wall of lactic acid bacteria. Antonie Van Leeuwenhoek. 1999;76:159-84.

190. Chapot-Chartier M-P, Kulakauskas S. Cell wall structure and function in lactic acid bacteria. Microb Cell Fact. 2014;13:9.

191. Liu Y, Perez J, Hammer LA, Gallagher HC, De Jesus M, Egilmez NK, et al. Intravaginal administration of interleukin 12 during genital gonococcal infection in mice induces immunity to heterologous strains of Neisseria gonorrhoeae. mSphere. 2018;3:e00421-17.

192. Shida K, Kiyoshima-Shibata J, Kaji R, Nagaoka M, Nanno M. Peptidoglycan from lactobacilli inhibits interleukin-12 production by macrophages induced by Lactobacillus casei through Toll-like receptor 2-dependent and independent mechanisms. Immunology 2009:128:e858-69

193. Choi S-H, Lee S-H, Kim MG, Lee HJ, Kim G-B. Lactobacillus plantarum CAU1055 ameliorates inflammation in lipopolysaccharide-induced RAW264.7 cells and a dextran sulfate sodium-induced colitis animal model. J Dairy Sci. 2019;102:6718-25.

194. Wu Z, Pan D-d, Guo Y, Zeng X. Structure and anti-inflammatory capacity of peptidoglycan from Lactobacillus acidophilus in RAW-264.7 cells. Carbohydr Polym. 2013;96:466-73.

195. Song J, Lang F, Zhao N, Guo Y, Zhang H. Vaginal lactobacilli induce differentiation of monocytic precursors toward Langerhans-like cells: in vitro evidence. Front Immunol. 2018;9:2437.

196. Torcia MG. Interplay among vaginal microbiome, immune response and sexually transmitted viral infections. Int J Mol Sci. 2019;20:266.

197. Mastromarino P, Cacciotti F, Masci A, Mosca L. Antiviral activity of Lactobacillus brevis towards herpes simplex virus type 2: role of cell wall associated components. Anaerobe. 2011;17:334-6.

198. Bron PA, Tomita S, van Swam II, Remus DM, Meijerink M, Wels M, et al. Lactobacillus plantarum possesses the capability for wall teichoic acid backbone alditol switching. Microb Cell Fact. 2012;11:123.

199. Andre G, Deghorain M, Bron PA, van Swam II, Kleerebezem M, Hols $P$, et al. Fluorescence and atomic force microscopy imaging of wall teichoic acids in Lactobacillus plantarum. ACS Chem Biol. 2011;6:366-76.

200. Tomita S, Irisawa T, Tanaka N, Nukada T, Satoh E, Uchimura T, et al. Comparison of components and synthesis genes of cell wall teichoic acid among Lactobacillus plantarum strains. Biosci Biotechnol Biochem. 2010;74:928-33.

201. Hardy L, Cerca N, Jespers V, Vaneechoutte M, Crucitti T. Bacterial biofilms in the vagina. Res Microbiol. 2017;168:865-74.

202. Jung S, Park O-J, Kim AR, Ahn KB, Lee D, Kum K-Y, et al. Lipoteichoic acids of lactobacilli inhibit Enterococcus faecalis biofilm formation and disrupt the preformed biofilm. J Microbiol. 2019;57:310-15.

203. Kim AR, Ahn KB, Yun C-H, Park O-J, Perinpanayagam H, Yoo Y-J, et al. Lactobacillus plantarum lipoteichoic acid inhibits oral multispecies biofilm. J Endod. 2019:45:310-5.

204. Vidal K, Donnet-Hughes A, Granato D. Lipoteichoic acids from Lactobacillus johnsonii strain La1 and Lactobacillus acidophilus strain La10 antagonize the responsiveness of human intestinal epithelial HT29 cells to lipopolysaccharide and gram-negative bacteria. Infect Immun. 2002:70::2057-64
205. Ahn JE, Kim H, Chung DK. Lipoteichoic acid isolated from Lactobacillus plantarum maintains inflammatory homeostasis through regulation of Th1- and Th2-induced cytokines. J Microbiol Biotechnol. 2019;29:151-9.

206. Pericolini E, Perito S, Castagnoli A, Gabrielli E, Mencacci A, Blasi $\mathrm{E}$, et al. Epitope unmasking in vulvovaginal candidiasis is associated with hyphal growth and neutrophilic infiltration. PLOS ONE. 2018;13:e0201436.

207. Hassan AN, Frank JF, Shalabi SI. Factors affecting capsule size and production by lactic acid bacteria used as dairy starter cultures. Int J Food Microbiol. 2001;64:199-203.

208. Poole J, Day CJ, von Itzstein M, Paton JC, Jennings MP. Glycointeractions in bacterial pathogenesis. Nat Rev Microbiol. 2018;16:440-52.

209. Laiño J, Villena J, Kanmani P, Kitazawa H. Immunoregulatory effects triggered by lactic acid bacteria exopolysaccharides: new insights into molecular interactions with host cells. Microorganisms. 2016;4:27.

210. Badel S, Bernardi T, Michaud P. New perspectives for lactobacilli exopolysaccharides. Biotechnol Adv. 2011;29:54-66.

211. Shukla A, Mehta K, Parmar J, Pandya J, Saraf M. Depicting the exemplary knowledge of microbial exopolysaccharides in a nutshell. Eur Polym J. 2019;119:298-310.

212. Salazar N, Gueimonde M, de los Reyes-Gavilán CG, Ruas-Madiedo P. Exopolysaccharides produced by lactic acid bacteria and bifidobacteria as fermentable substrates by the intestinal microbiota. Crit Rev Food Sci Nutr. 2016;56:1440-53.

213. Ruas-Madiedo P, Medrano M, Salazar N, De Los Reyes-Gavilán CG, Pérez PF, Abraham AG. Exopolysaccharides produced by Lactobacillus and Bifidobacterium strains abrogate in vitro the cytotoxic effect of bacterial toxins on eukaryotic cells. J Appl Microbiol. 2010;109::2079-86.

214. Gamar-Nourani L, Blondeau K, Simonet J-M. Influence of culture conditions on exopolysaccharide production by Lactobacillus rhamnosus strain C83. J Appl Microbiol. 1998:85:664-72.

215. Lin T, Chen C, Chen B, Shaw J, Chen Y. Optimal economic productivity of exopolysaccharides from lactic acid bacteria with production possibility curves. Food Sci Nutr. 2019;7:2336-44.

216. Bertsch A, Roy D, LaPointe G. Enhanced exopolysaccharide production by Lactobacillus rhamnosus in co-culture with Saccharomyces cerevisiae. Appl Sci. 2019;9:4026

217. Sánchez J-I, Martínez B, Guillén R, Jiménez-Díaz R, Rodríguez A. Culture conditions determine the balance between two different exopolysaccharides produced by Lactobacillus pentosus LPS26. Appl Environ Microbiol. 2006;72:7495-502.

218. Imran MYM, Reehana N, Jayaraj KA, Ahamed AAP, Dhanasekaran D, Thajuddin N, et al. Statistical optimization of exopolysaccharide production by Lactobacillus plantarum NTMI05 and NTMI20. Int J Biol Macromol. 2016;93:731-45.

219. Cheng X, Huang L, Li K-t. Antioxidant activity changes of exopolysaccharides with different carbon sources from Lactobacillus plantarum LPC-1 and its metabolomic analysis. World J Microbiol Biotechnol. 2019;35:68.

220. Patten DA, Laws AP. Lactobacillus-produced exopolysaccharides and their potential health benefits: a review. Benef Microbes. 2015;6:457-71.

221. Rahbar Saadat Y, Yari Khosroushahi A, Pourghassem Gargari B. A comprehensive review of anticancer, immunomodulatory and health beneficial effects of the lactic acid bacteria exopolysaccharides. Carbohydr Polym. 2019;217:79-89.

222. El-Deeb NM, Yassin AM, Al-Madboly LA, El-Hawiet A. A novel purified Lactobacillus acidophilus 20079 exopolysaccharide, LA-EPS-20079, molecularly regulates both apoptotic and NF-KB inflammatory pathways in human colon cancer. Microb Cell Fact. 2018;17:29.

223. Tukenmez U, Aktas B, Aslim B, Yavuz S. The relationship between the structural characteristics of lactobacilli-EPS and its ability to induce apoptosis in colon cancer cells in vitro. Sci Rep. 2019;9:8268.

224. Allonsius CN, van den Broek MFL, De Boeck I, Kiekens S, Oerlemans EFM, Kiekens F, et al. Interplay between Lactobacillus rhamnosus GG and Candida and the involvement of exopolysaccharides. Microb Biotechnol. 2017:10:1753-63.

225. Meade KG, O'Farrelly C. $\beta$-defensins: Farming the microbiome for homeostasis and health. Front Immunol. 2019;9:3072.

226. Donnarumma G, Molinaro A, Cimini D, De Castro C, Valli V, De Gregorio V, et al. Lactobacillus crispatus L1: high cell density cultivation and exopolysaccharide structure characterization to highlight 
potentially beneficial effects against vaginal pathogens. BMC Microbiol. 2014;14:137.

227. Sudbery PE. Growth of Candida albicans hyphae. Nat Rev Microbiol. 2011;9:737.

228. Machado D, Castro J, Palmeira-de-Oliveira A, Martinez-de-Oliveira J, Cerca N. Bacterial vaginosis biofilms: challenges to current therapies and emerging solutions. Front Microbiol. 2016;6:1528.

229. Chen Z, Zhang Z, Zhang H, Xie B. Analysis of the oxidative stress status in nonspecific vaginitis and its role in vaginal epithelial cells apoptosis. Biomed Res Int. 2015;2015:795656.

230. Hoang T, Toler E, DeLong K, Mafunda NA, Bloom SM, Zierden HC, et al. The cervicovaginal mucus barrier to HIV-1 is diminished in bacterial vaginosis. PLoS Pathog. 2020;16:e1008236.

231. Zhang L, Liu C, Li D, Zhao Y, Zhang X, Zeng X, et al. Antioxidant activity of an exopolysaccharide isolated from Lactobacillus plantarum C88. Int $J$ Biol Macromol. 2013;54:270-5.

232. Li B, Du P, Smith EE, Wang S, Jiao Y, Guo L, et al. In vitro and in vivo evaluation of an exopolysaccharide produced by Lactobacillus helveticus KLDS1.8701 for the alleviative effect on oxidative stress. Food Funct. 2019;10:1707-17.

233. Zhou X, Zhang K, Qi W, Zhou Y, Hong T, Xiong T, et al. Exopolysaccharides from Lactobacillus plantarum NCU116 enhances colonic mucosal homeostasis by controlling epithelial cell differentiation and c-Jun/ Muc2 signaling. J Agric Food Chem. 2019;67:9831-9.

234. Zhou X, Qi W, Hong T, Xiong T, Gong D, Xie M, et al. Exopolysaccharides from Lactobacillus plantarum NCU1 16 regulate intestinal barrier function via STAT3 signaling pathway. J Agric Food Chem. 2018;66:9719-27.

235. Sims IM, Ryan JLJ, Kim SH. In vitro fermentation of prebiotic oligosaccharides by Bifidobacterium lactis HNO19 and Lactobacillus spp. Anaerobe. 2014;25:11-7.

236. Ispirli H, Demirbaş F, Dertli E. Glucan type exopolysaccharide (EPS) shows prebiotic effect and reduces syneresis in chocolate pudding. J Food Sci Technol. 2018;55:3821-6.

237. Rios-Covian D, Cuesta I, Alvarez-Buylla JR, Ruas-Madiedo P, Gueimonde M de. Los Reyes-Gavilán CG. Bacteroides fragilis metabolises exopolysaccharides produced by bifidobacteria. BMC Microbiol. 2016;16:150.

238. Rodrigues L, Banat IM, Teixeira J, Oliveira R. Biosurfactants: potential applications in medicine. J Antimicrob Chemother. 2006;57:609-18.

239. Franzetti A, Tamburini E, Banat IM. Applications of biological surface active compounds in remediation technologies. In: Sen R, editor. Biosurfactants. New York: Springer New York; 2010. pp. 121-34.

240. Van Hamme JD, Singh A, Ward OP. Physiological aspects. Part 1 in a series of papers devoted to surfactants in microbiology and biotechnology. Biotechnol Adv. 2006;24:604-20.

241. Naughton PJ, Marchant R, Naughton V, Banat IM. Microbial biosurfactants: current trends and applications in agricultural and biomedical industries. J Appl Microbiol. 2019;127:12-28.

242. Mujumdar S, Joshi P, Karve N. Production, characterization, and applications of bioemulsifiers (BE) and biosurfactants (BS) produced by Acinetobacter spp.: a review. J Basic Microbiol. 2019;59:277-87.

243. Mouafo TH, Mbawala A, Ndjouenkeu R. Effect of different carbon sources on biosurfactants' production by three strains of Lactobacillus spp. Biomed Res Int. 2018:2018:1-15.

244. Haque F, Alfatah M, Ganesan K, Bhattacharyya MS. Inhibitory effect of sophorolipid on Candida albicans biofilm formation and hyphal growth. Sci Rep. 2016;6:23575

245. Itapary Dos Santos C, Ramos Franca Y, Duarte Lima Campos C, Quaresma Bomfim MR, Oliveira Melo B, Assuncao Holanda R, et al. Antifungal and antivirulence activity of vaginal Lactobacillus spp. products against Candida vaginal isolates. Pathogens. 2019;8:150.

246. Ceresa C, Tessarolo F, Caola I, Nollo G, Cavallo M, Rinaldi M, et al. Inhibition of Candida albicans adhesion on medical-grade silicone by a Lactobacillus-derived biosurfactant. J Appl Microbiol. 2015;1 18:1116-25.

247. Morais IMC, Cordeiro AL, Teixeira GS, Domingues VS, Nardi RMD, Monteiro AS, et al. Biological and physicochemical properties of biosurfactants produced by Lactobacillus jensenii P6A and Lactobacillus gasseri P65. Microb Cell Fact. 2017;16:155.

248. Gudiña EJ, Teixeira JA, Rodrigues LR. Isolation and functional characterization of a biosurfactant produced by Lactobacillus paracasei. Colloids Surf B Biointerfaces. 2010;76:298-304.
249. Spurbeck RR, Arvidson CG. Lactobacillus gasseri surface-associated proteins inhibit Neisseria gonorrhoeae adherence to epithelial cells. Infect Immun. 2012:80:3743.

250. Foschi C, Salvo M, Cevenini R, Parolin C, Vitali B, Marangoni A. Vaginal lactobacilli reduce Neisseria gonorrhoeae viability through multiple strategies: an in vitro study. Front Cell Infect Microbiol. 2017;7:502.

251. Jiang X, Yan X, Gu S, Yang Y, Zhao L, He X, et al. Biosurfactants of Lactobacillus helveticus for biodiversity inhibit the biofilm formation of Staphylococcus aureus and cell invasion. Future Microbiol. 2019;14::1133-46.

252. Satpute SK, Mone NS, Das P, Banat IM, Banpurkar AG. Inhibition of pathogenic bacterial biofilms on PDMS based implants by L. acidophilus derived biosurfactant. BMC Microbiol. 2019:19::39.

253. De Gregorio PR, Parolin C, Abruzzo A, Luppi B, Protti M, Mercolini L, et al. Biosurfactant from vaginal Lactobacillus crispatus BC1 as a promising agent to interfere with Candida adhesion. Microb Cell Fact. 2020;19:133.

254. Oleksy-Sobczak M, Klewicka E. Optimization of media composition to maximize the yield of exopolysaccharides production by Lactobacillus rhamnosus strains. Probiotics Antimicrob Proteins. 2020;12:774-83.

255. Fraunhofer ME, Jakob F, Vogel RF. Influence of different sugars and initial $\mathrm{pH}$ on $\beta$-glucan formation by Lactobacillus brevis TMW 1.2112. Curr Microbiol. 2018;75:794-802.

256. Banat IM, Satpute SK, Cameotra SS, Patil R, Nyayanit NV. Cost effective technologies and renewable substrates for biosurfactants' production. Front Microbiol. 2014;5:697.

257. Bertrand B, Martínez-Morales F, Rosas-Galván NS, Morales-Guzmán D, Trejo-Hernández MR. Statistical design, a powerful tool for optimizing biosurfactant production: a review. Colloids Interfaces. 2018;2:36.

258. Li N, Wang Y, Zhu P, Liu Z, Guo B, Ren J. Improvement of exopolysaccharide production in Lactobacillus casei LC2W by overexpression of $\mathrm{NADH}$ oxidase gene. Microbiol Res. 2015;171:73-7.

259. Reid G. The need to focus on therapy instead of associations. Front Cell Infect Microbiol. 2019;9:327.

260. Ravel J, Brotman RM. Translating the vaginal microbiome: gaps and challenges. Genome Med. 2016;8:35.

261. Ling Z, Liu X, Chen W, Luo Y, Yuan L, Xia Y, et al. The restoration of the vaginal microbiota after treatment for bacterial vaginosis with metronidazole or probiotics. Microb Ecol. 2013;65:773-80.

262. Petrova MI, Lievens E, Malik S, Imholz N, Lebeer S. Lactobacillus species as biomarkers and agents that can promote various aspects of vaginal health. Front Physiol. 2015;6:81.

263. Romero R, Hassan SS, Gajer P, Tarca AL, Fadrosh DW, Nikita L, et al. The composition and stability of the vaginal microbiota of normal pregnant women is different from that of non-pregnant women. Microbiome. 2014;2:4.

264. Vitali B, Pugliese C, Biagi E, Candela M, Turroni S, Bellen G, et al. Dynamics of vaginal bacterial communities in women developing bacterial vaginosis, candidiasis, or no infection, analyzed by PCR-denaturing gradient gel electrophoresis and real-time PCR. Appl Environ Microbiol. 2007;73:5731-41.

265. Zhou X, Westman R, Hickey R, Hansmann MA, Kennedy C, Osborn TW, et al. Vaginal microbiota of women with frequent vulvovaginal candidiasis. Infect Immun. 2009;77:4130-5.

266. Liu M-B, Xu S-R, He Y, Deng G-H, Sheng H-F, Huang X-M, et al. Diverse vaginal microbiomes in reproductive-age women with vulvovaginal candidiasis. PLOS ONE. 2013;8:e79812.

267. Mayer BT, Srinivasan S, Fiedler TL, Marrazzo JM, Fredricks DN, Schiffer JT. Rapid and profound shifts in the vaginal microbiota following antibiotic treatment for bacterial vaginosis. J Infect Dis. 2015;212:793-802.

268. Freitas AC, Chaban B, Bocking A, Rocco M, Yang S, Hill JE, et al. The vaginal microbiome of pregnant women is less rich and diverse, with lower prevalence of Mollicutes, compared to non-pregnant women. Sci Rep. 2017;7:9212.

269. Jespers V, Kyongo J, Joseph S, Hardy L, Cools P, Crucitti T, et al. A longitudinal analysis of the vaginal microbiota and vaginal immune mediators in women from sub-Saharan Africa. Sci Rep. 2017;7:11974.

270. Nowak RG, Randis TM, Desai P, He X, Robinson CK, Rath JM, et al. Higher levels of a cytotoxic protein, vaginolysin, in Lactobacillus-deficient community state types at the vaginal mucosa. Sex Transm Dis. 2018:45:e14-7.

271. Ata B, Yildiz S, Turkgeldi E, Brocal VP, Dinleyici EC, Moya A, et al. The endobiota study: comparison of vaginal, cervical and gut microbiota 
between women with stage 3/4 endometriosis and healthy controls. Sci Rep. 2019;9:2204.

272. Borgogna JC, Shardell MD, Santori EK, Nelson TM, Rath JM, Glover ED, et al. The vaginal metabolome and microbiota of cervical HPVpositive and HPV-negative women: a cross-sectional analysis. BJOG 2020;127:182-92.

273. Tortelli BA, Lewis WG, Allsworth JE, Member-Meneh N, Foster LR, Reno $H E$, et al. Associations between the vaginal microbiome and Candida colonization in women of reproductive age. Am J Obstet Gynecol. 2020;222:471.e1-471.e9.
274. Verwijs MC, Agaba SK, Darby AC, van de Wijgert JHHM. Impact of oral metronidazole treatment on the vaginal microbiota and correlates of treatment failure. Am J Obstet Gynecol. 2020;222:157.e1-157.e13.

\section{Publisher's Note}

Springer Nature remains neutral with regard to jurisdictional claims in published maps and institutional affiliations.
Ready to submit your research? Choose BMC and benefit from:

- fast, convenient online submission

- thorough peer review by experienced researchers in your field

- rapid publication on acceptance

- support for research data, including large and complex data types

- gold Open Access which fosters wider collaboration and increased citations

- maximum visibility for your research: over $100 \mathrm{M}$ website views per year

At BMC, research is always in progress.

Learn more biomedcentral.com/submissions 